NBER WORKING PAPER SERIES

\title{
TAKING STOCK OF TRADE POLICY UNCERTAINTY: EVIDENCE FROM CHINA'S PRE-WTO ACCESSION
}

\author{
George A. Alessandria \\ Shafaat Y. Khan \\ Armen Khederlarian \\ Working Paper 25965 \\ http://www.nber.org/papers/w25965 \\ NATIONAL BUREAU OF ECONOMIC RESEARCH \\ 1050 Massachusetts Avenue \\ Cambridge, MA 02138 \\ June 2019, Revised August 2022
}

We are extremely grateful to Mario Crucini, Costas Arkolakis, Yan Bai, Mark Bils, Dario Caldara, Dan Lu, Kim Ruhl, and Joseph Steinberg for numerous comments and suggestions. We also thank seminar participants at the University of Rochester, the 2019 Federal Reserve Trade Dynamics Workshop and the Spring 2019 Midwest Macroeconomics Meetings (UGA). The views expressed herein are those of the authors and do not necessarily reflect the views of the National Bureau of Economic Research.

NBER working papers are circulated for discussion and comment purposes. They have not been peerreviewed or been subject to the review by the NBER Board of Directors that accompanies official NBER publications.

(C) 2019 by George A. Alessandria, Shafaat Y. Khan, and Armen Khederlarian. All rights reserved. Short sections of text, not to exceed two paragraphs, may be quoted without explicit permission provided that full credit, including $\odot$ notice, is given to the source. 
Taking Stock of Trade Policy Uncertainty: Evidence from China's Pre-WTO Accession

George A. Alessandria, Shafaat Y. Khan, and Armen Khederlarian

NBER Working Paper No. 25965

June 2019, Revised August 2022

JEL No. E32,E60,F12,F13,F14

\begin{abstract}
$\underline{\text { ABSTRACT }}$
We study the effects on international trade from the annual tariff uncertainty about China's MFN status renewal in the U.S. prior to joining the WTO. We have four main findings. First, in the monthly data trade increases significantly in anticipation of uncertain future increases in tariffs and falls upon renewal. Second, the probability of a tariff increase was perceived to be relatively small, with an average annual probability of non-renewal of about 3.2 percent. Third, what matters more is the expected future tariff rather than the uncertainty around it. We identify these effects using within-year variation in the risk of trade policy changes around the renewal vote and trade flows. We show that an $(\mathrm{s} ; \mathrm{s})$ inventory model generates this behavior and that variation in the strength of the stockpiling in advance of the vote is increasing in the storability of goods. Fourth, the costs associated with the trade policy induced stockpiling reduce entrants' incentive to operate in a market with tariff uncertainty. Our results explain why trade may hold up in advance of a prospective policy change, such as Brexit or the U.S.-China escalating tariff war of 2018-19, but may fall sharply even if expected tariff increases do not materialize.

George A. Alessandria

Department of Economics

University of Rochester

Harkness 204

Rochester, NY 14627

and NBER

george.alessandria@ rochester.edu

Shafaat Y. Khan

World Bank EAP Research Center

Kuala Lumpur

Malaysia

sykhan@worldbank.org

Armen Khederlarian

1376 Storrs Road

Unit 4021 WB Young 315

Department of Agricultural and Resource Economics

Storrs, CT 06269

United States

armen.khederlarian@uconn.edu
\end{abstract}




\section{Introduction}

As the World rethinks the benefits of globalization, the path of future trade policy has become increasingly uncertain. This uncertainty requires firms making long-lived decisions to participate in foreign markets to form expectations over the future path of tariffs. Forecasting this path can be challenging as the timing, size, and likelihood of policy changes are all uncertain. Yet firms do form these expectations and move on. In this paper, we show how to estimate the path of expected future tariffs based on the behavior of firms in advance of a possible policy change whose size and timing are known but whose probability is not. We apply these ideas to China's annual renewal of normal trade relations (NTR) status in the United States prior to its access to the World Trade Organization (WTO).

We have four main findings. First, using monthly data, we find that trade increases significantly in anticipation of uncertain future increases in tariffs and then drops after the uncertainty resolution. Second, the probability of a tariff increase is estimated to be relatively small, with an average probability of non-renewal of about 3.2 percent and annual probabilities that range from 1 to 7 percent. Third, the expected future tariff is the primary driver of trade dynamics instead of uncertainty about the path of tariffs. The "wait-andsee" real option force from uncertainty only slightly weakens the incentives to anticipate the future tariff increase. Fourth, we find that costs associated with trade policy uncertainty (TPU) induced stockpiling reduce the value of entering and thus provide a new mechanism to understand the trade dampening effect of uncertainty in the annual data (Pierce and Schott, 2016; Handley and Limao, 2017; Graziano et al., 2020).

We use the timing of the annual renewal of China's NTR status and within-year variation in trade flows around this renewal to identify the impact of uncertain future changes in trade policy. Our identification leverages the fact that the NTR status renewal decision was legislated to occur in the summer of each year. Thus, prior to renewal, firms faced greater near-term risk about trade policy than immediately after Congress renewed NTR. Using a triple difference approach, we show that trade flows rose when facing a risk of higher tariffs in the months in advance of the renewal decision but then fell off sharply when renewal occurs. Essentially, trade policy risk induced a seasonal component into the within-year trade flows that was related to the expected change in trade policy and the ability of goods to be stored. This seasonal was eliminated when China joined the WTO.

Our findings can be best understood through the lens of an $(\underline{s}, \bar{s})$ inventory model applied to international trade as in Alessandria et al. (2010b). In this model, firms purchase a storable commodity infrequently to economize on a fixed ordering cost and hold larger inventories as a buffer in the presence of demand uncertainty. Firms trade off higher inventory costs 
against lower international transaction costs. Facing an uncertain future increase in tariffs, firms shift the timing of their purchases so they have relatively high purchases and stocks of inventories in advance of the possible tariff increase. Upon a successful renewal and fixed tariffs for the next 12 months, firms already hold large stocks in inventory and hence are less likely to purchase until they have run down their stockpiles. These effects are larger for goods for which holding inventories is less costly in the model and the data. When the risk of a tariff increase is eliminated there is no longer an incentive to bunch trade flows in certain times of the year.

To estimate the probability of non-renewal we simulate the inventory model for many heterogeneous industries and run the same regressions as in the data. Each industry differs in policy risk as in the data and some unobserved fundamental parameters. On policy, industries face a different tariff risk but a common non-renewal probability and date. To capture the tendency for industries with more storable goods to have larger booms and busts in exports to the United States around the possible tariff increase, we allow industries to differ in terms of the fixed ordering costs and their inventory costs, captured by the depreciation rate. These are the two main parameters that determine lumpiness in trade. We vary the relationship between the ordering costs and inventory costs to match two empirical facts. First, we match the non-TPU related trade lumpiness of each industry. Second, we match the estimated differential response of a high and low storable good to the risk of non-renewal. Hence, our probability estimate matches, both the average swing in trade around non-renewal along with the differential response by product storability.

The finding that possible future increases in tariffs increase trade in advance of the uncertainty resolution stands in contrast to previous findings in the literature because we are using within-year variation in trade flows rather than annual trade flows. Our approach is complementary to other approaches that identify the role of TPU as it operates at a different frequency ${ }^{1}$ and is based on within-year shipment decisions of firms already active in the export market. This analysis generates a time-varying path of the probability of non-renewal that can then be plugged into models of the export decision. By compounding these probabilities, we find that nearing its access to the WTO in 2001, China's probability of retaining its MFN status to the U.S. market is much higher than those estimated in other studies such as Handley and Limao (2017).

Moreover, equipped with a model that captures the dynamics of trade flows in the presence of uncertainty, we more generally quantify the role of pure uncertainty in the presence of inventory holdings and fixed costs of ordering. In particular, we compare the trade-

\footnotetext{
${ }^{1}$ Unlike the decision to export, which depends on trade policy over the next 5 to 10 ten years, the amount ordered depends on trade policy in an order cycle which tends to be 3-4 moths.
} 
dampening wait-and-see effect of uncertainty with the trade-boosting effect of an expected tariff hike. We simulate multiple spreads around the same expected tariff increase and decompose the anticipatory growth into the contribution of the first moment and the second moment. The results indicate that the standardized effect of an expected tariff change is 4.4 times the effect of pure uncertainty and almost all the variation in anticipatory import growth is explained by just the expected tariff change.

We also show that the documented effects of TPU on within-year trade flows during this episode can be related to the well-documented fact that annual trade flows - the sum of monthly trade flows - were relatively low for high tariff gap industries before China joined the WTO. Specifically, we use our model to show that the anticipatory de-stocking and stockpiling from TPU entails additional inventory holding costs that increase overall costs and reduce the value of importing from China. In our model, we find that this stockpiling behavior lowers firms' annual profits by about 3-7 percent for a possible tariff hike of 30 percent that would last 1 year. The effects are much larger for smaller firms and suggests the frictions we emphasize complement the existing explanations on sunk export costs as the TPU induced stockpiling costs lower the value of entering new export markets.

This paper is most related to early work evaluating the impact of uncertainty on international trade. Starting with Baldwin (1986), Baldwin and Krugman (1989) and Dixit (1989), models with sunk costs of exporting have been employed to argue that uncertainty depresses trade, since entering firms prefer to wait and see how uncertainty resolves. While entry and exit decisions have been shown to be important in international trade (Roberts and Tybout (1997), Alessandria and Choi (2007)), we focus on the behavior of incumbent firms in the short window before the resolution of uncertainty.

Recent papers have used models with sunk costs of exporting and found large effects of uncertainty on trade in various episodes of TPU (Crowley et al. (2018), Feng et al. (2017), Handley and Limao (2014)). ${ }^{2}$ One of the most studied episode is precisely the renewal of China's MFN status during the 1990s. Although applied tariffs on U.S. imports from China did not change after its accession to the WTO, Pierce and Schott (2016) find that U.S. industries most exposed to the threat of protectionist tariffs experienced large declines in employment and increased imports from China after the threat was eliminated. Handley and Limao (2017), using the structure of a sunk cost model, find that reduced uncertainty accounted for one third of China's export growth. By comparing trade patterns between 2000 and 2005, their model-implied probability of MFN access reversal is 13 percent, nearly three times as large as our estimates from within-year trade flows. Alessandria et al. (2021)

\footnotetext{
${ }^{2}$ Caldara et al. (2020) develop a model with sunk export costs but find that any TPU induced trade declines are due to investment adjustments costs and sticky prices.
} 
also study the effects of uncertain trade policy on the path of China's integration, but over a long period including the two prior liberalizations. They find greater uncertainty about reforms in the 1980s but estimate similar probabilities of non-renewal as we find here.

Our approach to studying the link between trade policy uncertainty and trade complements previous work by focusing on high frequency trade patterns, overcoming concerns of confounding long run factors or dynamics. ${ }^{3}$ In particular, in our model firms stockpile in the months before uncertainty is resolved thereby leading to a rise in trade. ${ }^{4}$ In contrast with this literature, in our framework, pure uncertainty has little impact on trade patterns as anticipation is mostly driven by expected trade cost changes. In this sense, our results are more in line with Steinberg (2019), who finds a minimal impact of TPU on the UK's aggregate trade due to Brexit. Our framework provides an alternative mechanism to explain why the UK's trade did not experience any declines despite the looming threat of Brexit. Indeed, there is substantial evidence that companies in Britain and Europe stockpiled imports in advance of possible Brexit dates and the actual date and this lead to booms and busts in trade similar to what we find in U.S.-China trade around the time of the MFN renewal votes. $^{5}$

There is a growing literature that applies inventory models to explain high frequency dynamics of international trade at the producer level or in the propagation of shocks. In Alessandria et al. (2010a), stronger inventory management considerations in international trade are shown to have contributed to the sudden drop in trade during the Great Recession, while in Alessandria et al. (2010b) inventory adjustments explain import and pricing dynamics of retail goods following large devaluations in emerging economies. In Bekes et al. (2017) demand volatility raises the motive for precautionary inventory holdings and explains variation in trade lumpiness across French exporter markets. These papers as well as ours build on the non-convexities from fixed ordering or shipment costs, that have been widely documented. ${ }^{6}$ Novy and Taylor (2020) also study the role of time-varying uncertainty in an inventory model, but are more focused on uncertainty in macroeconomic fundamentals.

Our paper is also related to some recent papers that study anticipation of policy changes. Baker et al. (2021) show that households increase their stocks in anticipation of a future sales tax rate increase. Khan and Khederlarian (2021) find de-stocking by U.S. imports

\footnotetext{
${ }^{3}$ For instance, Alessandria and Choi (2014) find trade grows gradually in the United States following a cut in trade costs owing to the slow dynamics of entry, exit, and firm expansion.

${ }^{4} \mathrm{Ruhl}$ (2011) uses a similar framework to estimate the expected duration of a worldwide temporary export ban of Canadian beef following the discovery of a cow infected with Bovine Spongiform Encephalopathy.

${ }^{5}$ See the report form the UK's Official of Official Statistics, "Did UK firms stockpile items ahead of the Brexit deadline?". In Appendix A and Figure C.1 we discuss and show how U.K. imports and exports behaved in anticipation of possible and eventual Brexit dates.

${ }^{6}$ See Alessandria et al. (2010b), Kropf and Saure (2014), Blum et al. (2019).
} 
from Mexico to upcoming tariff reductions from NAFTA substantially biases estimates of the trade elasticity. Unlike these papers, we study the effects of an uncertain policy change that did not materialize.

The rest of the paper is organized as follows. Section 2 lays out a model in which stockpiling in anticipation of a possible tariff rise increases trade before the resolution of uncertainty. We show that the trade boost is increasing in the probability of the tariff hike. In Section 3 we show that exports from China to the United States rose in anticipation of the resolution of China's MFN status renewal more in products that either had a high tariff gap or were more storable. In Section 4 we calibrate the model to many heterogeneous industries and then simulate it to match the anticipatory growth of Chinese exports to the United States during this episode to determine the probability of MFN status being revoked. In Section 5 we separate the contribution to the anticipatory increase in trade of pure uncertainty (second moment) versus the expected tariff change (first moment). In Section 6 we show how the frictions giving rise to the observed within-year variation in trade flows in higher tariff gap industries lower annual profits and provide a complementary explanation for the cross-industry variation in trade flows emphasized elsewhere. In the final section, we conclude.

\section{Model: Anticipation to TPU through Inventories}

While previous work on trade policy uncertainty has focused on firms' export entry decisions (Handley and Limao (2017), Crowley et al. (2018), Steinberg (2019), Caldara et al. (2020) and Alessandria et al. (2021)), we study how it affects the shipment decisions of incumbent firms. Lumpiness in trade flows is pervasive and there is strong evidence that exporters ship their goods infrequently to economize on the fixed costs of shipments (Alessandria et al. (2010b), Kropf and Saure (2014), Hummels and Schaur (2013), Bekes et al. (2017)). When facing a possible tariff increase, a firm deciding on when to export (import) has strong incentives to expedite their shipments before tariffs might be raised. This section describes a model in which imports rise as firms stockpile in anticipation of TPU resolution and then implode immediately afterwards, leading to sharp short-run reversals in trade flows. In particular, we introduce TPU into a standard $(\underline{s}, \bar{s})$ inventory model as in Alessandria et al. $(2010 \mathrm{~b}){ }^{7}$

\footnotetext{
${ }^{7}$ Other models with durable goods, such as capital or durable consumer goods, display similar anticipation effects. We chose an inventory model because inventory dynamics have been proven to be very successful in accounting for the short run dynamics of international trade flows (See Alessandria et al. (2010b), Alessandria et al. (2010a), Charnavoki (2019)).
} 


\subsection{Environment}

We consider a partial equilibrium model of an industry in which goods are storable and a continuum of monopolistically competitive retailers decide whether to import or not every period. Ordering entails a fixed shipment cost, causing firms to order infrequent but large shipments. On top of the fixed cost, retailers face demand uncertainty and a one period delivery lag, leading to precautionary inventory holdings. These frictions give rise to a $(\underline{s}, \bar{s})$ policy, where producers run down their inventories to a level $\underline{s}$ and then replenish it up to $\bar{s}$. Retailers are identical except for their history of demand shocks, that determines their current inventory holdings.

Let $p_{r g t}$ denote the prices charged by retailer $r$ in industry $g$ in period $t$ and $d_{r g t}$ its demand shock. Importers face a constant elasticity demand,

$$
c_{r g t}=e^{d_{r g t}} p_{\text {rgt }}^{-\sigma},
$$

where $\sigma$ is the elasticity of substitution. The variable cost of importing is common to all retailers in the same industry and equal to $\omega_{g t}=\omega\left(1+\tau_{g t}\right)$, where the tariff $\tau_{g t}$ belongs to a finite set, $T$. This implies that suppliers are perfectly competitive and that that the tariff pass-through is complete. ${ }^{8}$ TPU is reflected in the Markov process of $\tau_{g t}$, which has a transition matrix denoted by $\Pi^{\tau}$. At the beginning of each period retailers observe their inventory holdings, $s_{\text {rgt }}$ and their demand shock, $d_{r g t} \sim^{i i d} N\left(0, \sigma_{d}^{2}\right)$, assumed to be i.i.d. across firms and time ${ }^{9}$, and then price their good and decide to import or not. To import, retailers incur a industry-specific fixed cost $f_{g}$. We assume that imports cannot be returned, $z_{\text {rgt }} \geq 0$. Because of demand uncertainty, importers will never run down their inventories to zero, $\underline{s}_{g}>0$, and because of the delivery lag, sales never exceed current inventory holdings,

$$
q_{r g t}=\min \left[e^{d_{r g t}} p_{r g t}^{-\sigma}, s_{r g t}\right] .
$$

Assuming imports $\left(z_{r g t}\right)$ in transit depreciate at the same rate, $\delta_{g}$, as in the warehouse, the law of motion for the inventories is

$$
s_{r g, t+1}=\left(1-\delta_{g}\right)\left[s_{r g t}+z_{r g t}-q_{r g t}\right] .
$$

Next, we characterize the optimal policies and the tariff process. To simplify the notation we drop the firm, industry and time subscript. The firm's value of adjusting is denoted by $V^{a}(s, d ; \tau)$ and not adjusting by $V^{n}(s, d, \tau)$. Every period, retailers optimize by choosing

\footnotetext{
${ }^{8}$ Perfectly competitive suppliers rule out changes in import prices in response to the possible tariff hike. We test this in the empirical section.

${ }^{9}$ The idiosyncratic demand shocks smooth the industry distribution over inventories. Without demand shocks the distribution would be degenerate and any shock to tariffs would lead to permanent oscillations.
} 
$V(s, d ; \tau)=\max \left[V^{a}(s, d ; \tau), V^{n}(s, d ; \tau)\right]$, where

$$
\begin{aligned}
V^{a}(s, d ; \tau) & =\max _{p, z>0} q(p, s, d) p-(1+\tau) \omega i-f_{g}+\beta E V\left[s^{\prime}, d^{\prime} ; \tau^{\prime} \mid s ; \tau\right] \\
V^{n}(s, d ; \tau) & =\max _{p} q(p, s, d) p+\beta E V\left[s^{\prime}, d^{\prime} ; \tau^{\prime} \mid s ; \tau\right]
\end{aligned}
$$

are subject to (2) and (3). Solving for the optimal policies generates a $(\underline{s}, \bar{s})$ ordering policy that depends on current inventory holdings and the demand shock, $z=z(s, d, \tau)$. Similarly, the pricing schedule is characterized by a constant markup over the discounted marginal value of an additional unit of inventory next period, $p=\frac{\sigma}{\sigma-1} \frac{1-\delta}{\beta} V_{s^{\prime}}\left(s^{\prime}, d^{\prime} ; \tau^{\prime}\right)$. When facing a possible increase in $\tau^{\prime}$, importers trade off importing sooner and avoiding the risk at the expense of paying the fixed cost today and incurring higher inventory holding costs. In what follows we describe how this trade-off leads to different anticipatory dynamics under different tariff processes.

\subsection{Trade Policy Uncertainty and Anticipatory Stockpiling}

We introduce TPU into this environment by formulating a non-stationary Markov process in the form of a time-dependent transition matrix, denoted by $\Pi_{t}^{\tau}$. Allowing importers to anticipate possible tariff changes leads them to stockpile before the resolution of the uncertainty. In line with the empirical application in the next section, we fix the period in which uncertainty is resolved. ${ }^{10}$ Let $m_{\text {res }}$ be the last period before the possible tariff change, so that in period $m_{\text {res }}+1$ the uncertainty is resolved, then

$$
\Pi_{t}^{\tau}=\left\{\begin{array}{ll}
I_{|T|} & \text { if } t \neq m_{\text {res }} \\
\tilde{\Pi}^{\tau} & \text { if } t=m_{\text {res }}
\end{array} \quad, \quad \tilde{\Pi}^{\tau}=\left[\begin{array}{cc}
(1-\pi) & \pi \\
0 & 1
\end{array}\right]\right.
$$

Conditional on $\left(\pi, \tau^{\prime}\right)$, the key parameters determining the anticipation to a possible tariff change are the fixed cost of ordering and the depreciation rate. In section 4 we perform a rigorous quantification of the model aimed at estimating the perceived likelihood of China's MFN access revocation. For now, we calibrate the model to illustrate the qualitative response to TPU. Table 1 describes the parameter values chosen for this purpose. The demand elasticity is set equal to 4 , a standard value in the literature. We follow Alessandria et al. (2010b) in the rest of the parameter value choices. The fixed cost per order is set to 0.095 relative to the median revenue, the standard deviation of demand shocks to 0.8 and the depreciation rate to an annualized value of 30 percent. The model is calibrated at the monthly frequency by setting the discount rate $\beta$ equal to $0.97^{1 / 12}$, which yields a three

\footnotetext{
${ }^{10}$ In general, there can be uncertainty about the timing of a possible policy change. However, U.S. Congress voting on the renewal of China's MFN status took place every year by July and August. For more see section 3.1. Results with an uncertain resolution are presented in the appendix.
} 
percent annual interest rate. Jointly these parameters determine a median inventory-sales ratio of 3.64 months and an annual concentration of trade flows or Herfindahl-Hirschman (HH) index of 0.32 .

We now show that, conditional on a tariff increase, the anticipatory stockpiling is increasing in the probability of the tariff hike materializing. Initially, trade is tariff-free, i.e. $\tau=0$. In period $m_{\text {res }}+1$, importers of industry $g$ face the possibility of either remaining at 0 or facing a tariff of 10 percent. Hence, the set of possible set of tariffs is $T_{g}=\{0,0.10\}$. Afterwards, the new state is absorbing in the sense that $\tau_{g t}=\tau_{g, m_{\text {res }}+1} \forall t>m_{\text {res }}+1$, i.e. the tariff level will remain unchanged. ${ }^{11}$ To study how trade responds to different probabilities of the same tariff increase taking place, we vary transition probabilities in $\tilde{\Pi}_{m_{\text {res }}}^{\tau}$. In particular, importers face either a 0, 20, 50 or 100 percent chance of tariffs being raised to 10 percent. We assume importers have 12 months to anticipate this event.

Figure 1 plots the aggregate industry response of imports. In all cases, the expected tariff increase does not materialize. For all non-zero probabilities, imports rise in anticipation of the uncertainty resolution and then drop sharply afterwards. This reversal in trade flows is short-lived. Imports start rising only in the two to three months before the resolution of uncertainty. ${ }^{12}$ The magnitude of the trade reversals around the time of the uncertainty resolution are clearly increasing in the probability of the tariff rise. However, qualitatively the responses are very similar. Figure 2 illustrates that the anticipatory rise is paralleled by a similarly strong increase in the aggregate inventory-sales ratio. Since importers want to avoid paying possibly higher tariffs, they stockpile so that after the resolution they hold high levels of inventories. The inventory-sales ratio reaches its peak in the month of uncertainty resolution. With a 50 percent chance of renewal, the inventory-sales ratio is around 35 percent above its equilibrium level. Again, the strength of these effects depends on the probability importers assign to the tariff increase. Once, uncertainty is resolved, trade drops temporarily as importers have amassed enough inventories to satisfy their demand.

Finally, note that these dynamics take place in a window of 5 months before and 5 months after the resolution of uncertainty. Figure 3 shows the time-varying $(\underline{s}, \bar{s})$ bands where the firms in the top-left region orders positive quantities and firms to the bottom-right do not order. The second line denotes the amount of inventories ordering firms will bring into the next period, which does not depend on the demand shock given it is iid. The initial ordering policy (solid black line) is the same as the ordering policy 12 months ahead of the anticipated change (line with circles). However, there are two notable changes in the ordering policy

\footnotetext{
${ }^{11}$ The results are nearly identical when the tariff is in place for only one year.

${ }^{12}$ Before imports start rising, echo-effects lead to temporary drops in imports in month 8 . These are due to importers timing their purchases similarly to have enough inventories before the possible increase in tariffs while saving on the fixed ordering cost
} 
one month before the anticipated change. First, the $\underline{s}$ moves to the right indicating an increase in the ordering region. Secondly, the gap between $\bar{s}$ and $\underline{s}$ increases, indicating larger orders. ${ }^{13}$ In the application we study in this paper, uncertainty over China's MFN tariff access was repeated annually for more than 10 years. However, a convenient feature of this framework is that the trade reversals around the uncertainty resolution settle before the beginning of next year's anticipatory dynamics. ${ }^{14}$ This allows us to focus on just a single episode of uncertainty resolution when estimating the probability of MFN reversal in section 4. Before doing that, we first show that the observed anticipatory dynamics of U.S. imports from China in response to the threat of MFN tariff access revocation were similar to those documented in this section.

\section{Seasonal Effects of China's TPU Episode}

We now document that the annual possibility of tariff hikes during the 1990s induced strong seasonal patterns in China's exports to the United States. Between 1991 and 2000, every year around July and September, the U.S. Congress voted on revoking China's MFN status. While previous studies have focused on the long run changes from the elimination of this risk when China joined the WTO in 2001, we exploit the within-year variation of the tariff risk during the 1990s. Once Congress had voted, MFN rates were secured at least for another 12 months. We find that in the months prior to the voting, exports of industries that faced the largest risk spiked. Once the voting had taken place their exports plummeted.

\subsection{Background}

During the 1990s, U.S. imports from China were subject to substantial policy uncertainty as China's access to MFN tariffs had to be renewed annually (see Handley and Limao (2017), Pierce and Schott (2016), Crowley et al. (2018)). With the advent of the Cold War, the United States applied protectionist non-Normal Trade Relations (NNTR), also known as column 2 tariff rates, established by the Smoot-Hawley Tariff Act of 1930 to non-market economies. Under the Trade Act of 1974, the United States granted MFN access to nonmarket economies conditional on (1) the existence of a bilateral commercial agreement and (2) the compliance of freedom-of-emigration requirement. For one, the United States and China signed a trade agreement in 1980. For two, the U.S. President was given authority to waive the second requirement on annual renewable basis, subject to approval by the U.S. Congress. This second condition was the source of annual uncertainty. In the 1980s the

\footnotetext{
${ }^{13}$ Ordering policy three months ahead of the change shows that firms economize on the fixed ordering costs by delaying the orders to one month right before the expected increase in tariffs.

${ }^{14}$ In Figure 3 we show that the steady state policy functions exactly overlap with the ones 12 months before the anticipated policy change.
} 
annual renewal of China's MFN status was carried out without any political considerations. But after the events of the Tiananmen Square in 1989, revocation of China's MFN status gained central attention as a measure of political sanction. Every year after 1990 and until 2000, the U.S. Congress voted on the disapproval of the President's renewal. Although China's MFN access was never actually revoked it came close in 1990, 1991 and 1992 when the House passed legislation to revoke it but the Senate failed to sustain the vote. Revocation would have led to the imposition of NNTR tariff rates that on average were 10 times larger than MFN rates.

The political process that determined the annual renewal of China's MFN status was characterized by a relatively fixed calendar. The President's authority to renew China's MFN access expired every year on the 3rd of July. In every year, the President indeed executed the waiver immediately before its expiration. After the renewal, Congress had 60 days to consider a disapproval vote on the Presidential renewal. Voting would generally take place between the end of July and beginning of August. ${ }^{15}$ Only in 1992 the political process stretched into the beginning of October as the Senate finally failed to override President Bush's veto. Hence, in all other years, uncertainty regarding the renewal of China's MFN status was resolved between July and August.

\subsection{Empirical Strategy}

Our identification of the seasonal effects of the uncertainty regarding China's annual MFN status renewal is based on (1) cross-industry, and (2) within year variation of the risk. With respect to the former, we follow Pierce and Schott (2016) and Handley and Limao (2017) and exploit the cross-industry variation in the tariff hike that would have occurred if China's access to MFN rates had been revoked. Our measure of the tariff risk is $X_{g} \equiv$ $\max _{t}\left\{\ln \left(\left(1+\tau_{g}^{N N T R}\right) /\left(1+\tau_{g t}^{M F N}\right)\right)\right\} .{ }^{16}$ On the one hand, the tariff risk was sizeable and relatively constant throughout the 1990s. Figure 4 indicates that the median NNTR gap is around 25 percentage points and the only minor variation over time occurred between 1995 and 1997, when MFN rates fell slightly due to the agreements of the Uruguay Round. On the other hand, there was substantial cross-industry variation in the tariff risk. Figure 5 shows that for an industry in the 10th percentile the gap was less than 5 percentage points, while applied tariffs of an industry in the 90th percentile would have increased by more than 60 percentage points.

The use of the within-year variation of the tariff risk constitutes a novel insight into

\footnotetext{
${ }^{15}$ Figure C.2 of the Appendix contains the dates of all U.S. Congress votes concerning episode.

${ }^{16}$ Using a time invariant measure of the NNTR gap increases the sample size since for some years the NNTR gap is missing. Results are robust to using the time-varying gap or the gap in 1999.
} 
this episode. ${ }^{17}$ As described above, every year U.S. importers knew that tariffs on Chinese imports could increase if the President did not renew the waiver by the $3^{\text {rd }}$ of July or if in the next 60 days U.S. Congress disapproved the waiver. Hence, by the end of August of every year, importers were certain that rates would remain the same at least until the beginning of July of the following year. In other words, by the end of August and following the approval of China's access to MFN rates, expected tariffs equaled the MFN rate at least until July of the following year. In the model of section 2, the possibility of a tariff hike leads importers to increase their imports in anticipation of uncertainty resolution. The fixed timing of the uncertainty resolution during this episode serves as an excellent laboratory to test the empirical relevance of the short-run effects of TPU modelled above. Moreover, the use of the within-year tariff risk overcomes several concerns associated with the comparison of trade flows over longer periods of time to identify TPU (Handley and Limao, 2017; Crowley et al., 2018), such as correlated supply shocks or the existence of pre-trends (Alessandria et al., 2021).

To identify the within-year variation of Chinese exports to the United States due to the risk of MFN access reversal we follow a standard triple difference approach. The goal of this approach is to purge Chinese exports to the U.S. from confounding seasonalities that are unrelated to the tariff risk. Each of the three differences enables us to address different sources of potential seasonal effects. First, U.S. imports from China relative to the aggregate of the rest of the World (RoW) allow us to eliminate U.S.-specific demand seasonalities such as toy sales during Christmas. Second, Chinese exports to the U.S. relative to its exports to the 15 European Union (E.U.) member countries in 1990 allow us to control for Chinaspecific supply seasonalities such as China's New Year celebration. ${ }^{18}$ Third, the inclusion of trade flows until 2007 allows us to compare bilateral seasonalities before and after the year 2000 — when China had gained PNTR access. Our baseline estimation equation is as follows:

$$
\begin{aligned}
\ln \left(v_{m-2: m}^{i j g t} / v_{m-7: m-5}^{i j g t}\right) & =\sum_{m=1}^{12} \beta_{m} \mathbb{1}\{t<2001\} \mathbb{1}\{i=U . S .\} \mathbb{1}\{j=\text { China }\} \mathbb{1}\left\{m=m^{\prime}\right\} X_{g} \\
& +\gamma_{i j t m}+\gamma_{i j g m}+\gamma_{g t m}+\varepsilon_{i j g t m},
\end{aligned}
$$

where $i$ denotes the importer, $j$ the exporter, $g$ a HS-6 industry, $t$ the year, $m$ the calendar month, and $v$ is the CIF import value.

We now discuss the left and right hand side of (5). For each month $m$, the dependent

\footnotetext{
${ }^{17}$ In recent work, Bianconi et al. (2021) and Greenland et al. (2021) exploit the within year variation of the tariff risk during this episode to assess the impact of TPU on firm's equity valuation.

${ }^{18}$ The 15 countries are Austria, Belgium, Denmark, France, Finland, Germany, Greece, Ireland, Italy, Luxembourg, the Netherlands, Spain, Sweden, the UK and Portugal.
} 
variable is defined as the growth rate of average imports between $m$ and $m-2$ relative to the average between $m-7$ and $m-5$. The motivation of this choice is twofold. First, using a within-year growth rate allows us to more precisely capture fluctuations in monthly trade flows. Second, the use of 3-month averages allows us to smooth out some of the lumpiness in trade flows at HS-6 level. In section 3.5 we show that the results are robust to using alternative dependent variables such as the log of annual import share. Importantly, in the model simulation of section 4 we use the same dependent variable as specified in (5). Finally, note that the use of within year growth rates eliminates any confounding factor that varies at annual frequency, such as applied tariff rates.

On the right hand side, $\left\{\beta_{m}\right\}_{m=1}^{12}$ capture the differential monthly response of U.S. imports from China before its PNTR access to the risk of MFN access revocation. It is estimated for each month $m=[1,12]$ by interacting the tariff risk $X_{g}$ with an indicator variables for U.S. imports from China prior to 2001. The specification of the fixed effects is standard and controls for the different sources of seasonalities discussed above. First, $\gamma_{i j t m}$ controls for changes in seasonality at the country pair level; second, $\gamma_{i j g m}$ controls for average seasonalities in the country pair and industry level; and, third, $\gamma_{g t m}$ controls for changes in seasonalities at the industry level.

One potential concern of our approach is that the tariff risk due China's annual MFN status renewal may have induced seasonal effects in U.S. imports from other countries or in Chinese exports to other countries through general equilibrium effects. In that sense,

the estimates $\left\{\hat{\beta}_{m}\right\}_{m=1}^{12}$ may capture the net effect of the seasonal in U.S. imports from China before 2001 relative to the other trade flows. However, in subsection 3.5 we show that the estimated seasonal effects under the triple difference approach are unchanged when considering each of the different reference trade flows separately.

\subsection{Data}

We use monthly trade flows at the 6-digit level of the Harmonized System (HS) product classification. U.S. imports are from the Census Bureau and E.U. import data from Eurostat. Imports are in CIF value of imports for consumption. MFN and NNTR rates at HS-8 product level are from Feenstra et al. (2002). We take the median of each HS-8 product to define the tariff risk at the HS-6 level. Our baseline sample period includes the years 1991 to 2007. The baseline sample is restricted to those industries that were traded at least once every year between the United States and China in years before China's WTO accession. We do this because the mechanism we study in this paper abstracts from market entry and exit decisions. This sample includes 1,812 HS-6 industries. These industries account for 95 percent of the total Chinese exports to the United States in 1990, 86 percent in 2001 and 80 
percent in 2007 .

\subsection{Baseline Results}

In Figure 6 we present the estimates of $\left\{\hat{\beta}_{m}\right\}_{m=1}^{12} \cdot{ }^{19}$ There is a distinct pattern in the growth rates of trade flows in response to the tariff risk. By May imports become significantly elastic to the tariff risk as goods facing larger gaps grow stronger than goods facing lower gaps. The effect peaks in June and remains significantly high in July and August. Growth rates then decline and become significantly negative in November, reaching its trough in January. Trade remains significantly low until February. At its peak (trough), for the median tariff risk (31pp), imports are on average 8 percent higher ( 8 percent lower) than compared to its reference period. Overall the peak to trough elasticity, calculated as $\max _{m}\left\{\beta_{m}\right\}-\min _{m}\left\{\beta_{m}\right\}$, is 0.62 and reported at the bottom of Tables 2 to $4 .{ }^{20}$ Note that in the estimation of the likelihood of MFN reversal below we will match the peak to trough estimate documented here.

These results show that throughout the entire year exports from China to the United States responded significantly to the threat of facing a tariff hike. U.S. importers anticipated the possibility of a tariff hike by increasing their purchases before the resolution of uncertainty. When the tariff hike didn't materialize, imports dropped in the beginning of the year. This TPU induced seasonal pattern in U.S.-China trade flows indicates that importers indeed assigned a non-zero probability to the non-renewal of China's MFN status. However, the magnitude of the anticipatory response was rather small. ${ }^{21}$

\subsection{Robustness}

The baseline result is robust to several alternative estimates of the effect of the tariff risk of losing MFN status on U.S. imports from China. Here we document the seasonal pattern under alternative specifications of the reference trade flows, the outcome variable, and the sample.

Alternative Reference Trade Flows. Our baseline estimate of the seasonal induced by TPU on U.S. imports from China during the 1990s considers a triple difference. Here we study how the results hold up if instead we had used fewer reference trade flows to control for seasonal effects. This may shine light on the importance of general equilibrium effects -

\footnotetext{
${ }^{19}$ The precise coefficients and standard errors are reported in the first column of Table 2.

${ }^{20}$ Note that the cumulative effect, i.e. $\sum_{m=1}^{12} \hat{\beta}_{m}=-0.38$, is consistent with, and surprisingly close, to the trade dampening effect of the tariff risk at the annual frequency documented in Pierce and Schott (2016) and Handley and Limao (2017).

${ }^{21}$ To provide a comparison, Khan and Khederlarian (2021) estimate short run anticipatory elasticities during the NAFTA phaseouts to be around 4 to 6 . Importantly, in the episode studied here tariff changes are uncertain and observed anticipation is the result of underlying expectations.
} 
seasonality induced by China's tariff risk on non-U.S.-China trade flows - in our baseline estimates. Table 2 reports the effect of the NNTR gap on U.S. imports from China prior to 2001 including different trade flows. Note that in all these cases we continue to fully saturate the empirical model used to identify $\left\{\beta_{m}\right\}_{m=1}^{12}$, as indicated by the fixed effects at the bottom of the Table. Column 1 reports the baseline estimate including the three differences. In columns two to four we consider each one of the differences as the only reference group (difference). In all three cases the seasonal pattern is very similar to the baseline. This indicates that our baseline estimate is indeed driven by the seasonal in U.S. imports from China during the 1990s as opposed to U.S. imports from China after 2000, U.S. from the RoW, and Chinese exports to the E.U. Perhaps, the main difference with respect to the baseline lies in that the seasonal is slightly larger and its timing shifted by a month when considering Chinese exports only (column 3). This might be due larger cross-market substitution effects driven by the gap in Chinese exports than in U.S. imports. In columns five to seven we use different combinations of the three differences. Again, the peak to trough estimates at the bottom of the Table show that in all cases the estimates are very close to the baseline.

Alternative Dependent Variables. Our baseline dependent variable is a within-year growth rate and uses a moving average of imports. Here we explore the robustness of our results to these two choices. Table 3 reports the estimates of (5) under alternative dependent variables. Column 1 reports the baseline estimates. In column 2 we show that using a mid-point growth rate, i.e. $\frac{2\left(v_{m-2: m}^{i j g t}-v_{m-7: m-5}^{i j g t}\right)}{v_{m-2: m}^{i j g t}+v_{m-7: m-5}^{i j t}}$, yields the same results as the baseline, suggesting that zeros are not an important for the result. Columns three to six address the main concerns of our baseline dependent variable. column 3 shows that using the log import value alone continues to yield a large peak to trough estimate. However, two differences with respect to the baseline emerge. First, the peak occurs in July instead of June and the trough occurs in November instead of December. In effect this timing is still slightly closer to the timing implied by the model of section 2, suggesting that the use of the moving average tends to spread out the peak and trough. Second, the trough is larger than the peak. This indicates that the use of within-year growth tends to undermine the asymmetries in the peak and trough response. These findings are also present if the dependent variable is specified as the log annual share of monthly imports (column 4). Column 5 shows that the results are also similar when using the Poisson-pseudo maximum likelihood estimator that includes zero monthly import shares. Finally, comparing column 6 to column 4 confirms that the moving average tends shift the peak (trough) response a month forward (backward). Despite the differences with respect to our baseline estimate, we highlight that both, the peak and trough in the seasonal effects of TPU on U.S. imports from China under these alternative 
specifications, are statistically significant and their timing is in line with the political events of the episode and the mechanism described in section 2 .

Alternative Samples. Our baseline sample only includes industries with non-zero U.S. imports from China in every year between 1990 and 2000. The reason is that the mechanism explored in this paper excludes market entry and exit decisions. In columns 2 and 3 of Table 4 we consider the robustness of the baseline results to this choice. First, in column 2 we further restrict the sample to include only industries with non-zero annual U.S. imports from China until 2007. As expected, this does not change the results. In column 3 we include all industries. The TPU induced seasonal effect is slightly attenuated. We interpret this as evidence for the entry and exit decisions interacting with the tariff risk. In particular, we conjecture that new goods are more likely to be introduced during months when the tariff risk is low, thereby undermining the slump in the trade of incumbent industries. Similarly exiting industries are more likely to exit in the immediacy of the uncertainty resolution, thus attenuating the peak response. Finally, in columns 4 and 5 we show that the baseline results are robust to alternative groups of countries included in the aggregate trade flows of the RoW.

\subsection{TPU Effects and Storability}

Next we investigate how the response to the TPU-induced seasonality interacts with the product storability. In the model presented in section 2 the anticipatory response to a possible tariff hike is decreasing in the depreciation rate of the good and increasing in the fixed ordering cost. While both costs are generally not observed, lower deprecation rates and higher ordering costs are both associated with a higher inventory-sales ratio. Hence, we can test whether U.S. imports from China of goods that are characterized by higher inventorysales ratios also display a stronger peak to trough response to the risk of MFN revocation. We follow Khan and Khederlarian (2021) and proxy the average inventory-sales ratio of an industry — or its storability — with the average lumpiness of its trade flows net of unrelated determinants. We measure lumpiness as the annual inverse Herfindahl-Hirschman (HH) or concentration index of monthly trade flows. This measure can be interpreted as the average number of months in a year in which a good is ordered. Goods ordered less frequently are presumably held as inventories for longer periods of time. For its calculation we use U.S. imports from the 135 countries of the RoW between 1991 and 2000 at the HS-10 district of entry level and eliminate source-time fixed effects such as distance and aggregate shocks. ${ }^{22}$

\footnotetext{
${ }^{22}$ More precisely, we focus on HS-10 country varieties that were imported in every year between 1991 and 2000. The inverse HH index calculation at the HS-6 level proceeds as follows. First, we calculate the HH index of annual imports at the HS10-District of entry - denoted by $k$ - and country of origin $(j)$ level for
} 
We do so by estimating

$$
\begin{aligned}
\ln \left(v_{m-2: m}^{i j g t} / v_{m-7: m-5}^{i j g t}\right) & =\sum_{m^{\prime}} \beta_{m} \mathbb{1}\{t<2001\} \mathbb{1}\{i=U . S .\} \mathbb{1}\{j=\text { China }\} \mathbb{1}\left\{m=m^{\prime}\right\} X_{g} \\
& +\sum_{m} \beta_{m}^{H H} \mathbb{1}\{t<2001\} \mathbb{1}\{i=U . S .\} \mathbb{1}\{j=\text { China }\} \mathbb{1}\left\{m=m^{\prime}\right\} X_{g} \times\left(1 / H H_{g}\right) \\
& +\gamma_{i j t m}+\gamma_{i j g m}+\gamma_{g t m}+\varepsilon_{i j g t m} .
\end{aligned}
$$

Figure 8 plots the marginal effect of $X_{g}$ on the within-year import growth for a high and low storable good, defined respectively by the $10^{\text {th }}$ and the 90 percentile ${ }^{\text {th }}$ of the inverse $\mathrm{HH}$ index distribution. Precisely, the effect is calculated as $\hat{\beta}_{m}+\hat{\beta}_{m}^{H H} \times\left[1 / H H_{g}\right]$ with the inverse $\mathrm{HH}$ index being 2.4 for the low storable good and 4.5 for the high storable. The peak to trough response is more than twice as large for the more storable good; the peak to trough being 0.72 (0.16) for the high storable and 0.34 (0.14) for the low storable good (standard errors in parenthesis). ${ }^{23}$ These results indicate that the average response documented above is driven by goods that are relatively more storable. This is consistent with the anticipatory stockpiling mechanism that explains the within-year variation in trade flows in advance of a possible tariff hike in the model of section 2. In the next section, we discipline the model estimation of the likelihood of MFN access revocation to reproduce the documented interaction between storability and the TPU induced seasonal.

\section{The Likelihood of MFN Access Revocation}

We now use the model of section 2 to estimate the likelihood of MFN revocation. The model is calibrated to match the TPU-induced seasonality in imports documented above, both on average as well as across products that differ by storability. The main findings of this section are that (1) the probability of revocation was relatively small; and (2) it is largest in the early 1990s and drops as time goes on. To match the average response and differential responses by lumpiness across industry we vary the tariff gap, the costs of ordering, and the storing goods across industries. Modelling these technology differences across industries slightly lowers our estimate of the likelihood of non-renewal compared to using common industry technology or varying technology along a single dimension.

every year between 1990 and 2001. The HH index is defined as $H H_{j k t}=\sum_{m=1}^{12}\left(v_{m}^{j k t} / \sum v_{m}^{j k t}\right)^{2} \in[1 / 12,1]$. Next, we estimate $1 / H H_{j k t}=\delta_{0}+\delta_{k}+\delta_{j t}+u_{j k t}$ and then define the degree of storability as $\widehat{1 / H H}_{k}=\hat{\delta}_{0}+\hat{\delta}_{k}$. The source-year fixed effects net out determinants of lumpiness that are unrelated to storability. Finally, we define storability at the HS-6 level as the average over $\widehat{1 / H H}_{k}$, i.e. $(1 / H H)_{g}=1 / K \sum_{k}^{K} \widehat{1 / H H}_{k}$. Figure 7 shows the distribution of the resulting measure. The results in this subsection are robust to alternative calculations of the $\mathrm{HH}$ index as long as the good is defined at a sufficiently disaggregate level.

${ }^{23}$ The Wald test that considers the peak to trough of the high and low storable goods to be equal yields a F-statistic of 5.77 . 


\subsection{Calibration}

Our approach to estimate the likelihood of China's MFN access revocation matches the crossindustry variation in the tariff risk, the lumpiness of trade and the average and heterogeneous peak to trough response. To do so, two additional parameters that discipline the link between lumpiness and the anticipatory response are introduced to the model described in section 2 . Conditional on the likelihood of a tariff increase $(\pi)$ and the tariff risk $\left(\tau^{\prime}\right)$, the magnitude of the anticipatory rise and subsequent drop depends critically on the depreciation rate. Low $\delta$ goods respond stronger to the knowledge of a possible future tariff hike. This relationship is highly non-linear and hence a key determinant of the estimated probability. Given the lack of available measures of the depreciation rate we resort to the storability proxy used in section 3.6 - the inverse HH index - to calibrate industry-specific depreciation rates. Nevertheless, in the model, the inverse HH index is determined by both, the depreciation rate and the ordering cost. In particular, lumpiness is increasing in the ordering cost and decreasing in the depreciation rate. We specify the ordering cost to be a decreasing function of the depreciation rate, $f_{g}=\alpha_{0}\left(1+\delta_{g}\right)^{\alpha_{1}}$. Together $\left\{\delta_{g}\right\}, \alpha_{0}, \alpha_{1}$, and $\pi$ determine the model fit of the observed inverse $\mathrm{HH}$ index distribution, the average peak to trough response and the heterogeneity in the peak to trough response.

Common parameters. Several of the model's parameters are common across all calibrations. They are reported in Panel A of Table 5. The model is calibrated to the monthly frequency by setting $\beta=0.97^{(1 / 12)}$, equivalent to an annual interest rate of 3 percent. This value corresponds to the average difference between the 10-year Treasury rate and the realized CPI inflation between 1990 to 2004. Note that this choice implies a delivery lag of 1 month. The elasticity of substitution is set to be 2.7 , the short-run elasticity estimate in Khan and Khederlarian (2021). The standard deviation of demand shocks is set to 1, a value close to that in Alessandria et al. (2010b), and the mean demand shock $(\bar{d})$ is 0 .

Parameters calibrated to match heterogeneity. To match the industry heterogeneity as well as the heterogeneous response to the tariff risk we proceed in four steps. First, given $\alpha_{0}, \alpha_{1}$, we set $\delta_{g}$ and $f\left(\delta_{g}\right)$ of each (HS-6) industry $g$ so that the steady state inverse HH index matches the observed inverse $\mathrm{HH}$ index used in section 3.6 as the proxy of storability. ${ }^{24} \mathrm{We}$ also assign each industry the tariff set $T_{g}=\left\{0, \tilde{X}_{g}\right\}$, where $\tilde{X}_{g}=\max _{t}\left\{\tau_{g}^{N N T R}-\tau_{g t}^{M F N}\right\}$ is the same tariff risk used in the empirical analysis. ${ }^{25}$ Hence, each of the 1,812 HS-6 industries is characterized by the triplet $\left(\tilde{X}_{g}, \delta_{g}, f\left(\delta_{g}\right)\right)$. Second, we take 300 random draws from the

\footnotetext{
${ }^{24}$ In line with the empirical analysis, we calculate the inverse HH index of each industry as the mean inverse $\mathrm{HH}$ index at the more disaggregate firm level. We drop HS-6 industries with inverse HH indexes below the $0.5^{\text {th }}$ and above $99.5^{\text {th }}$ percentiles to eliminate noise from outliers.

${ }^{25}$ In what follows, a tilde on top of a variable indicates that it is obtained or used in model simulations.
} 
joint distribution $\left(\tilde{X}_{g}, \delta_{g}, f\left(\delta_{g}\right)\right)$ and simulate the aggregate transition path of each draw in response to the following shock process. ${ }^{26}$ Starting at the steady state without tariffs (MFN tariffs), firms know that in 12 months tariffs might rise by $\tilde{X}_{g}$ with probability $\pi$, common to all industries. ${ }^{27}$ Ex-post it does not occur. Third, we pool over all simulations to estimate the following two equations. First, the average peak to trough elasticity is obtained by the analog of (5),

$$
\ln \left(\tilde{v}_{m-2: m}^{g} / \tilde{v}_{m-5: m-7}^{g}\right)=\sum_{m=m^{\prime}} \beta_{m}^{s i m} \mathbb{1}\left\{m=m^{\prime}\right\} \ln \left(1+\tilde{X}_{g}\right)+\epsilon_{g m},
$$

where the dependent variable is the same growth rate we used in section 3 and $\tilde{v}_{m}^{g}$ are the monthly aggregate trade flows of each simulated industry. Second, the heterogeneous response by the degree of storability is obtained by the analog of (6),

$$
\begin{aligned}
\ln \left(\tilde{v}_{m-2: m}^{g} / \tilde{v}_{m-5: m-7}^{g}\right) & =\sum_{m=m^{\prime}} \beta_{m}^{s i m} \mathbb{1}\left\{m=m^{\prime}\right\} \ln \left(1+\tilde{X}_{g}\right) \\
& +\sum_{m=m^{\prime}} \beta_{m}^{H H, s i m} \mathbb{1}\left\{m=m^{\prime}\right\} \ln \left(1+\tilde{X}_{g}\right)\left(\widetilde{1 / H H_{g}}\right)+\epsilon_{g m} .
\end{aligned}
$$

At last, the probability of MFN access revocation is estimated by iterating over $\pi, \alpha_{0}, \alpha_{1}, \underline{\delta}$ until we match (1) the average peak to trough response in (8) and (2) the heterogeneous peak to trough response in (8). The target moment of the former is $\max _{m}\left\{\hat{\beta}_{m}^{\text {sim }}\right\}-\min _{m}\left\{\hat{\beta}_{m}^{\text {sim }}\right\}=$ 0.64 as found in the data; while the target moments of the latter are the constant peak to trough estimated as $\max _{m}\left\{\hat{\beta}_{m}^{s i m}\right\}-\min _{m}\left\{\hat{\beta}_{m}^{\text {sim }}\right\}$ and the peak to trough of the interaction term, $\max _{m}\left\{\hat{\beta}_{m}^{H H, \text { sim }}\right\}-\min _{m}\left\{\hat{\beta}_{m}^{H H, \text { sim }}\right\}$. Their estimates in the data are $1.29(0.29)$ and $-0.26(0.08)$, respectively (standard errors in parenthesis). ${ }^{28}$

\subsection{Baseline Result}

We find that to match the inverse $\mathrm{HH}$ index distribution and the average and heterogeneous peak to trough response to the tariff risk $\pi=3.22$ percent, $\alpha_{0}=1.1$, and $\alpha_{1}=-51$ percent per month as reported in Panel B of Table 5. Figure 9 plots the resulting distributions of $\delta_{g}$ and $f\left(\delta_{g}\right)$ and Figure 10 plots the model fit of the observed inverse HH index. The fit is almost perfect. Given these parameter values, the simulations of the industry transitions around the possible tariff hike $\tilde{X}_{g}$ perfectly match the average peak to trough elasticity of

\footnotetext{
${ }^{26}$ Each simulation takes around 5 minutes. While matching the distribution clearly matters for the estimate of $\pi$, when we repeat the procedure with 300 draws the differences are minimal.

${ }^{27}$ We simulate 24 months, but only keep months 6 to 17 to construct the data set. As can be seen in Figure 1 the trade dynamics generated by a possible tariff hike are sufficiently short lived not to affect the dynamics in successive year of TPU shocks.

${ }^{28}$ In a previous version of the paper we matched only the average anticipatory rise. Results matching only the rise yield a similar probability.
} 
0.62. Figure 12a illustrates the heterogeneity in this response by plotting the peak to trough elasticity of each industry (simulation) over the inverse HH index. More storable industries - lower inverse HH index — respond much stronger. Our baseline calibration disciplines this interaction by targeting the peak to trough of the constant and the interaction terms of (6) estimated in section 3.6. While the fit is not perfect it is reasonably close. Precisely, the constant peak to trough in the data is 1.29 and 1.42 in the baseline simulations, while the interaction term is -0.26 in the data and -0.25 in the baseline simulations.

Our estimate of the probability of non-renewal is lower than the one obtained by Handley and Limao (2017) in a framework that exploits the sensitivity of firms' market entry decision to TPU. ${ }^{29}$ Our focus on changes in trade within narrowly defined windows of time allows us to circumvent concerns of confounding the effect of the tariff risk with other long run changes that might have driven the trade patterns in the decade before and after China's WTO accession. Moreover, our mechanism is entirely different to theirs as it focuses on incumbent firms that are already operating in a market and solely decide the timing of their shipments. Nevertheless, in section 6 we show that the lower probability obtained here might still be reconciled with the higher probability estimated in a sunk cost model that matches the annual data given the loss in firm value caused by the TPU-induced seasonality.

\subsection{Robustness}

We investigate the robustness of the baseline result to alternative specifications of the industry heterogeneity and its sensitivity to the choice of common parameters. ${ }^{30}$ Throughout the different robustness checks we find that the probability of non-renewal consistently lies between 1.5 and 4.5 percent.

Only heterogeneity in the depreciation rate. Our baseline approach varies both, $\delta$ and $f$, to match the heterogeneous response to the risk of reverting to a NNTR tariff rate. Alternatively, we can vary only the depreciation rate to match the average and heterogeneous response to the tariff risk. To do so we first choose a common ordering cost $f_{g}=f=0.14$ to optimize the fit of the inverse HH index distribution. Figure 11a shows that this procedure also generates a good fit. Column 2 of Table 6 reports the results of this calibration. The probability drops to 2.61 percent. This is due to the highly non-linear relation between the depreciation rate and the anticipatory response to the tariff risk. Figure $12 \mathrm{~b}$ shows that as goods become more storable ( $\delta$ decreases), the anticipatory response rises exponentially. On the one hand, this non-linearity implies a 1 percentage point reduction relative to the

\footnotetext{
${ }^{29}$ Handley and Limao (2017) find the equivalent probability to be around 13 percent.

${ }^{30}$ In section B of the Appendix we show that our results are also robust to (1) updates or signals about the likelihood of non-renewal as nearing the resolution; and (2) early resolution of the uncertainty.
} 
baseline of the probability that matches the average response. On the other hand, it results in both, a constant and interaction term of the peak to trough of (8) that are much larger than the one found in the data. This counterfactual justifies the choice of using both $\delta$ and $f$ to match the heterogeneous response to the tariff risk.

Only heterogeneity in the ordering costs. In the model the $\mathrm{HH}$ index is jointly determined by the depreciation rate and the ordering cost. Column 3 of Table 6 , we report the estimated probability and heterogeneous responses when only varying $f_{g}$ and keeping the depreciation the same across industries. We set $\delta_{g}=\delta=1.95$ percent per month to optimize the fit of the inverse HH index distribution. Figure 11b illustrates that the fit is still quite good. ${ }^{31}$ The probability estimated under this approach is much lower at 1.5 percent. This low probability is due to the low depreciation rate required to match the inverse $\mathrm{HH}$ index distribution and the fact that the peak to trough elasticity is relatively constant in the ordering cost, as illustrated in Figure 12c. Another way to see this is that the peak to trough interaction term of (8) is much smaller than the baseline and the data, indicating that the relation between the inverse $\mathrm{HH}$ index and the peak to trough is undermined under this approach.

No industry heterogeneity. We now assess the impact on the baseline result when industries are only differentiated by the tariff risk they face. In particular, we set the depreciation rate and the ordering cost to be the median values of the baseline calibration, $\delta_{g}=\delta=4.48$ percent per month and $f_{g}=f=0.14$ (relative to median per period revenues). The results are reported in column 4 of Table 6. The resulting 3.63 percent probability of reversal is slightly higher than the baseline. Figure $12 \mathrm{~d}$ shows that the peak to trough elasticity is essentially constant in the tariff risk. Consistent with this finding, column 5 reports that using only 4 simulations, namely the $20^{\text {th }}, 40^{\text {th }}, 60^{\text {th }}$ and $80^{\text {th }}$ percentile of the distribution over $\tilde{X}_{g}$ yields an almost identical probability estimate. These results indicate that matching the response by the degree of storability reduces the estimated probability, as more storable goods require a smaller probability to yield the same anticipatory response and push up the mean response for the same probability.

Heterogeneity in the level of demand. In the baseline approach there is no significant effect on the overall level of trade, since the anticipatory rise and the subsequent drop tend to cancel each other out. To accommodate a level effect that interacts with the tariff risk we let the average demand depend on the tariff gap. On the one hand, as argued in Handley and Limao (2017), that effect shall be negative, as uncertainty dampens trade. On the

\footnotetext{
${ }^{31}$ For alternative values of $\delta$, the fit becomes poor on either one or the other side of the distribution.
} 
other hand, with producer heterogeneity the average productivity of exporting firms rises as the productivity threshold for entering increases with the tariff risk. Hence, the level of demand of the average exporting firms might increase with the tariff risk, while total exports decline. We explore both alternatives by setting all parameters at their baseline value and allowing the average level of industry demand — or mean demand shock $\bar{d}_{g}$ — to be linearly decreasing (increasing) in the tariff risk. The results are reported in columns 6 and 7 of Table 6. The estimated probability increases when the tariff risk dampens the level of trade, as lower levels of demand undermine the gains from stockpiling in advance of the tariff risk. The opposite occurs when demand rises with the tariff risk (selection). However, in both cases the deviation from the baseline estimate is at most 1 percentage point.

Sensitivity to common parameters. Table 7 reports the sensitivity of the estimated probability to alternative choices of the variance of the demand shock and the demand elasticity. For computational reasons, we use the result in column 5 of Table 6 - "No heterogeneity with few tariffs" - as the benchmark and only match the average response estimated by (7). Columns 2 and 3 show that the probability is slightly decreasing in the variance of demand, commonly interpreted as the precautionary motive of holding inventories. Having more inventories on hand on average, diminishes the incentives to stockpile in advance of a possible tariff hike. However, the magnitude is negligible, indicating that $\sigma_{d}$ is not critical in the determination of the probability. Columns 4 and 5 report the results when using a smaller and higher demand elasticity, respectively. For a higher (smaller) value of $\sigma$, the probability rises (drops) relative to the benchmark. The reason is that holding large levels of inventories becomes more attractive when revenues fall more (higher demand elasticity) in the event of a tariff hike. Again, the probabilities remain relatively low and close to the baseline estimate.

\subsection{Annual Probabilities}

Our baseline estimate of the probability of China's MFN access reversal fixes the peak and trough months to be the same in all years between 1990 and 2000. However, there was also annual variation in the timing of the uncertainty resolution. Here, we allow the resolution month to vary annually by first estimating the annual response to the tariff risk and then applying the probability estimation approach from above to obtain year-specific estimates. 
Precisely, we estimate ${ }^{32}$

$$
\begin{aligned}
\ln \left(v_{m-2: m}^{i j g t} / v_{m-7: m-5}^{i j g t}\right) & =\sum_{t=1990}^{2000} \sum_{m=1}^{12} \beta_{m, t} \mathbb{1}\left\{t=t^{\prime}\right\} \mathbb{1}\{i=U . S .\} \mathbb{1}\{j=\text { China }\} \mathbb{1}\left\{m=m^{\prime}\right\} X_{g t} \\
& +\gamma_{i j t m}+\gamma_{i j g m}+\gamma_{g t m}+\varepsilon_{i j g t m}
\end{aligned}
$$

Columns 1 and 2 of Table 8 report the peak and trough months of each year. Column 3 reports the estimates of the annual peak to trough elastcitity, $\max _{m}\left\{\hat{\beta}_{m}\right\}-\min _{m}\left\{\hat{\beta}_{m}\right\}$, and column 4 the model implied probabilities. There are three major takeaways. First, in all years the peak and trough responses align well with the timing of uncertainty resolution. The peak takes place between May and August, while the trough occurs between December and February. Second, the annual probabilities of non-renewal are in line with the contemporaneous political developments. ${ }^{33}$ The probability rises in 1990, reaches its peak in 1995 and then declines until the end of the decade. In 1990 the probability jumps to 3.5 percent, when the U.S. Congress came closest to reversing the President's renewal vote but the vote itself was a relative surprise. It then drops in the next years. ${ }^{34}$ In the years 1994-96 it reaches its maximum values of between 6 and 7 percent, coinciding with the arrival of President Clinton and a Democratic majority in the U.S. Senate and House of Representatives. During his Presidential campaign Clinton had announced he would link China's MFN status to its human rights record. After 1997 the probability of non-renewal becomes negligible until it rises again to 3.2 percent in 2000, coinciding with the vote on China's PNTR access. Third, averaging over the annual probabilities yields a probability of around 3.6 percent, slightly larger than the baseline. This is the result of relaxing the peak and trough months.

Finally, we use our estimated annual probabilities to infer the time-varying likelihood of China maintaining MFN status for the years until 2001 when the process of annual renewal ended with China's WTO accession. We can infer this likelihood by compounding our estimated annual probability of not revoking China's MFN status in the years prior to 2001. Figure 13 plots the result. Because of the overall low $\hat{\pi}$, in 1990 the probability that China would maintain its MFN status during the 1990s was around 65 percent. This probability grows as China MFN status is renewed annually until its WTO accession. In fact, even 3

\footnotetext{
${ }^{32}$ Note that here (1) we use the annual tariff risk $X_{g t}$ instead of its maximum and (2) that instead of the post-WTO indicator a dummy for each pre-WTO year is used. Thus, results are still relative to the average of the post-WTO period.

${ }^{33}$ Figure C.3, compares our measure of TPU based on trade patterns from the newspaper article counts measure by Pierce and Schott (2016). The main difference with respect to their measure lies in the relatively higher probability during the initial years of the Clinton administration

${ }^{34}$ In part the lack of significant peak to trough responses in 1991 and 1992 may be due to the fact that the voting stretched out for several months (See Figure C.2). One of the shortcomings of our approach is that such large uncertainty surrounding the time of uncertainty resolution inhibits the anticipatory response and hence undermines our identification.
} 
years before China obtaining PNTR status the perceived probability of maintained access to MFN rates was already around 95 percent.

\section{The Role of Uncertainty}

In this section we separate the effects of a change in expected tariffs from the effects of uncertainty about the change. The real options literature suggests that uncertainty about future tariffs will deter trade when there is an irreversible investment. ${ }^{35}$ The irreversibility of investments in such models necessitates a large gap between expected benefits and costs to incentivize entry, creating action and inaction regions within the state space. The importance of pure uncertainty depends on the sensitivity of these cutoffs and the distribution of firms around it. Given that the real options models have a similar stopping time formulation as the inventory model, we investigate the role of pure uncertainty in our model. First, we disentangle the effect of the expected change from the pure uncertainty or second moment of the tariff process in driving the anticipatory response to the possibility of China's MFN access revocation. We find uncertainty played a minor role in dampening the anticipatory response relative to the expected increase in tariffs. Second, we consider the role of pure TPU in the inventory model more generally showing that uncertainty only has a large effect for very large gaps in tariffs and larger non-renewal probabilities than we estimate.

\subsection{Uncertainty around China's MFN Renewal}

To assess the contribution of uncertainty in driving the results of section 4 we estimate the anticipatory response to the certainty equivalent of the expected tariff change. Specifically, we give each industry $g$ a change in tariffs equal to $\hat{\pi} \tilde{X}_{g}$ with certainty and estimate (7) with the simulated data. For a certain change of $\hat{\pi} \tilde{X}_{g}$, the $\max _{m}\left\{\hat{\beta}_{m}^{s i m}\right\}-\min _{m}\left\{\hat{\beta}_{m}^{s i m}\right\}$ is $0.79 .{ }^{36}$ This is higher than the estimate of 0.62 when the tariffs are expected to increase by $\tilde{X}_{g}$ with a probability of $\hat{\pi}$. Therefore, when we keep the expected increase in tariffs the same, we find that the uncertainty depresses the anticipatory response by around 25 percent on average. The negative effect of uncertainty is in line with the wait-and-see effect widely reported in the literature. It arises because the chance of the tariff rate remaining unchanged makes an advanced payment of the fixed ordering cost sub-optimal. However, overall, pure uncertainty plays a minor role in the anticipatory rise and subsequent drop in trade flow around the annual renewal vote as more than three quarters of the response is explained by the expected change.

To illustrate the mechanism, Figure 14 plots the ordering schedule the month before an

\footnotetext{
${ }^{35}$ See Bernanke (1983), Dixit (1989), Pindyck (1991) and more recently Kellogg (2014).

${ }^{36}$ See column 8 of Table 6 for the moments related to storability.
} 
expected tariff change of 40 percent. The blue line plots the ordering cutoff when the change occurs with certainty and the red line when the tariff remains the same or increases to 80 percent with equal probability. The region left of the lines are the ordering region - firms order when they have fewer inventories or a high demand shock. The ordering region in the uncertain case is significantly smaller than in the case of the certain change despite the same expected tariff change. The region between the two curves is the inaction region due to pure uncertainty. In this example, the expected tariff change is much larger than the ones faced by Chinese exporters during the 1990s even in the industries with the largest NNTR gap, given the small probability found in section 4 . In effect, in the next section we show that for small expected changes pure uncertainty plays a minor role.

\subsection{Uncertainty in Inventory Models}

Here we study the role of pure uncertainty in the inventory model of section 2 more generally. Precisely, we consider multiple spreads around the same expected tariff change as well as different levels of expected changes to illustrate two features of the anticipatory response to possible tariff hikes. First, the peak to trough elasticity is increasing in the expected tariff change. Second, the variance or the pure uncertainty component becomes relatively more important in dampening the peak to trough response as the expected tariff change increases. Because the implied probabilities (expected tariff hikes) we found in 4 were low, these findings explain why uncertainty contributed relatively little in driving the anticipatory rise to the NNTR threat.

In all simulations, the parameters are held constant at the values reported in Table 1, with exception of the expected tariff change. Hence, each simulation is characterized by the pair $\left\{T_{n}, \tilde{\pi}_{n}\right\}$, where $n$ denotes a simulation and $\tilde{T}_{n}=\left\{0, \tilde{X}_{n}\right\}$ is the set of possible tariffs, which we set to be either 0 or $\tilde{X}_{n}$. We consider multiple expected tariff increases ranging from 1 percentage point to 20 percentage points and multiple mean-preserving spreads around each one of them. For example, an expected tariff increase of 10 percentage points can occur through a 25 percent chance of a 40 percentage points increase or through a 50 percent chance of 20 percentage points increase. The peak to trough elasticities of all simulations are plotted in Figure 15. As expected, the response is increasing but more interestingly it is non-linear over $\tilde{\pi}_{n} \tilde{X}_{n}$. Moreover, conditional on an expected tariff change, the peak to trough is increasing in the probability of the change.

We formalize these findings by estimating different specifications that disentangle the role of the first, $\mathbb{E}\left(\tilde{X}_{n}\right)=\tilde{\pi}_{n} \tilde{X}_{n}$, and the second moment of the tariff risk, $\operatorname{Var}\left(\tilde{X}_{n}\right)=$ $\tilde{\pi}_{n}\left(1-\tilde{\pi}_{n}\right) \tilde{X}_{n}^{2} \cdot{ }^{37}$ Results are presented in Table 9. In all regressions the left hand side

\footnotetext{
${ }^{37}$ The formula for variance is determined by considering the tariff change as a Bernouli process where the
} 
variable is the import growth in the month before the uncertainty resolution as defined in previous sections. In the first two columns, we estimate the linear relationship between the anticipatory response and the expected tariff change. The positive coefficient captures precisely the trade boosting effect of an upcoming possible tariff hike. Moreover, it explains the majority of the variation as indicated by the high R-square. In column 3 we further include the square of the expected tariff change. The negative coefficient on the square term indicates that the linear relation between the anticipatory rise and the expected tariff change declines as the expected change increases, consistent with Figure 15. The R-square only increases slightly to 87 percent. In column 4 and 5 we introduce the pure uncertainty or variance term into the estimation. In both cases the coefficient on the variance is negative. This is the trade dampening effect. To compare the magnitude of the effect of the first and second moment, in column 4 we standardize all variables. The coefficient on the expected change is more than 2 times larger than that on the variance of the change. Column 5 shows that by including the first moment, the non-linear term and the variance, all the variation in the anticipatory trade response is captured and the R-square is 100percent.

Through the lens of an $(\underline{s}, \bar{s})$ inventory model, in section 4 we found that U.S. importers assigned a relatively low probability to the non-renewal of China's MFN status. This section illustrates that given this low probability, the trade dampening of uncertainty is minor. In the relevant region of the expected tariff change, the anticipation to the tariff risk is almost linear. However, when expected tariff changes become large, the anticipatory stockpiling flattens out and uncertainty strongly depresses the policy-induced seasonal in trade.

\section{TPU-Induced Stockpiling and Firm Entry}

This section investigates whether the forces giving rise to the within-year anticipatory stockpiling from TPU might also contribute to the low volume of annual trade flows. We build on the evidence that U.S. imports from China of high tariff gap industries grew relatively fast upon China's WTO accession, which has been the focus of prior work. While our results of section 3 demonstrated that there was also a shift to more stable within-year trade flows, here we argue that the seasonal stockpiling induced by the TPU raises inventory holding cost and lowers profits, which ultimately reduces trade. We explore these links by measuring the decline in firm value with the tariff gap and risk. Moreover, we consider how various modeling assumptions about firm heterogeneity and operating costs increase the elasticity of firm-value to the tariff gap.

To show how our model can generate low trade volume over the year, we consider how the value of entry into importing is falling in the tariff gap and risk. To separate the impact

only two outcomes are a tariff staying zero with probability $\left(1-\tilde{\pi}_{i}\right)$ or increasing to $X_{g}$ with probability $\tilde{\pi}_{g}$. 
of the near-term risk from the more distant, and repeated, risks emphasized by Handley and Limao (2017) we consider how being exposed to just one annual cycle of risk affects the firm's value. Specifically, we calculate the proportional change in firm value between a firm facing risk $(1+\tau, \pi)$ and no risk as,

$$
\Delta V(1+\tau, \pi)=\frac{E V_{-12}(0 ; 1+\tau, \pi)-E V(0 ; 1, \pi)}{(1-\beta) E V(0 ; 1,0)}
$$

where $E V_{-12}(0 ; 1+\tau, \pi)$ is the value of entering the market with no inventories (first state variable) 12 months before a possible tariff increase by $\tau$ percentage points with a probability $\pi .^{38}$ To concentrate on the short-run risk, we assume that any increase in tariff only lasts one year and that after that year there is free trade. ${ }^{39}$ We scale the difference in firm value by the annual flow value of firm with no tariff risk. The annual discount factor is denoted by $\beta=(1+r)^{-1}$. In essence, $\Delta V(\tau, \pi)$ is the proportional loss in the flow value of the firm facing one year of possible tariff risk relative to the flow value without uncertainty.

Figure 16 plots the change in the value of importing, $\Delta V(\tau, \pi)$, against the gross tariff gap, $1+\tau$ given two non-renewal probabilities, $\pi$, for the industry with the median storability. The first non-renewal probability of 4.5 percent is from our estimate for the entire pre-WTO period. Going from 0 to a 40 percent tariff lowers firm value by about 2 percent. The second value of the probability is 13.5 percent, quite close to the value from Handley and Limao (2017), and lowers firm value up to nearly 7 percent with a 40 percent tariff. Overall, the value from entering is falling with the expected tariff gap. For a fixed probability of nonrenewal, the loss in firm value increases with the tariff gap, but a at a decreasing rate as the wait-and-see mechanism becomes stronger with a higher tariff gap.

Our analysis so far is likely to understate the reduction in firm value from the increased inventory costs from tariff risk since it ignores both the costs firms face to operate in foreign markets and persistent firm heterogeneity. In terms of operating costs, since Das et al. (2007) nearly all empirical estimates of export participation models find substantial flow operating costs. $^{40}$ To explore the impact of this margin we introduce a monthly operating cost equal to 10 percent of average sales in an industry with no tariff gap. The middle line in Figure 16 shows this makes the value of importing much more elastic. We have also abstracted from any sources of persistent firm heterogeneity. It is well-known that this tariff risk is more of a concern for smaller firms. To capture this effect we explore the change in value for a firm whose demand is on average 25 percent lower than the size of the average firm and also faces a fixed operating cost. We compare the value of a small firm with tariff risk to a small firm

\footnotetext{
${ }^{38}$ With no tariff gap the expected value does not depend on the probability of non-renewal.

${ }^{39}$ If the tariff change was permanent then the change in firm value would roughly be 30 times larger than what we report.

${ }^{40}$ This fixed cost is different from ordering cost as it is paid regardless of the ordering behavior.
} 
with no tariff risk and find this makes profits around 3 times more elastic. Overall, for a 10 percent tariff gap, Pierce and Schott (2016) find trade is 4.8 percent lower in the data while our model suggests that the value of entering is 1 to 3.5 percent lower. Lower profits certainly discourage entry, or encourage exit, but the size of the effect depends on how many firms are at the margin and their characteristics.

Due to the expected rise in tariffs, firms stockpile by bringing forward their purchases which comes with additional inventory ordering and holding costs. This section shows that this force substantially discourages entry by lowering firm value which is more pronounced with higher expected tariffs, fixed operating costs and low demand.

\section{Conclusion}

The aim of this paper is four-fold. First, we show that uncertain future changes in tariffs have sizeable effects on trade flows in the interval before and after these proposed policy changes even when no change in tariff is realized. Second, we show how to use these trade dynamics through the lens of a standard $(\underline{s}, \bar{s})$ inventory model to identify the expected path of future trade policy. Third, we demonstrate that these frictions give rise to more costly inventory holdings, lowering firm value of importing and accounting for some of the crosssectional dampening of trade flows. Finally, we show that there is valuable information in high-frequency trade flows that is hidden by the common practice of annual aggregation.

China's annual U.S. NTR renewal provides the ideal setting to achieve these aims. In models with storable goods and fixed ordering costs, incumbent importers anticipate uncertain future trade policy changes by increasing their purchases before a possible policy change. Given two possible policy outcomes, the magnitude of anticipatory dynamics depend on three components of uncertainty, (1) the size of the policy change, (2) its probability, and (3) the amount of time until the uncertainty resolution. The features of China NTR fixes the timing and size of the policy change good-by-good and allows us to use the model to estimate the probability of the policy change. We find a lower mean probability of non-renewal than elsewhere but year-to-year variations that match up well with some other qualitative measures. Importantly, we show that the increase in trade flows of high tariff gap industries documented elsewhere also coincided with a substantial change in the way that those goods were ordered through the year.

We also use the model to distinguish between the role of pure uncertainty and the leveleffect of the expected tariff change. Even though the "wait-and-see" effect due to pure risk is present in the $(\underline{s}, \bar{s})$ model, its relative contribution is quite small relative to the first moment of the policy change.

A benefit and limitation of our approach to identify the path of future trade policy is 
that it hinges on a relatively short-run dynamic decision on the timing of purchases. As the frictions from trade and inventory costs lead importers to hold 3-4 months of imported inventories, future trade policy outside this window has almost no effect on ordering behavior. Thus our approach can be applied to numerous other episodes to estimate the near term path of policy. For instance import decisions soon after the Trump election can help identify the expected tariff in 2017. Likewise, trade and inventory flows in Britain and the E.U. provide insights to the expected date of Brexit. There were multiple rounds of precautionary stockpiling in advance of each possible exit date.

To learn about the longer-run path of trade policy, it will be useful to consider more durable investments such as exporting or FDI as in Alessandria and Mix (2018). Ruhl and Willis (2017) find that the expected duration of exporting of a new exporter is only about three years compared to 9 years for a continuing exporter and so perhaps by leveraging these different horizons we can recover a longer path of future trade policy. Of course, these alternative approaches must remain consistent with the behaviour identified in our study. Indeed, our estimates can be used as inputs into models with alternative margins that could be affected by TPU. Fortunately, our model is easily modified to include the decision to enter markets.

Finally, our results provide a mechanism to explain why trade held up fine in advance of a future policy change such as Brexit. Likewise, trade may not fall in the presence of an increase in tariffs provided they are expected to escalate further as in the case of the U.S.-China trade war of 2018-19. Our results suggest that trade could fall off sharply following a possible increase in tariffs that is unrealized owing to an inventory overhang, although general equilibrium considerations could mitigate this effect. Indeed, revisiting these findings in a general equilibrium framework would be useful to explore the effects of trade policy uncertainty on the aggregate economy. 


\section{References}

Alessandria, George and Carter Mix, "Trade Policy is Real News: An Analysis of Past, Present, and Future Trade Costs," 2018.

- and Horag Choi, "Do Sunk Costs of Exporting Matter for Net Export Dynamics?," The Quarterly Journal of Economics, 2007, 122(1), 289-336.

_ and _ , "Do falling iceberg costs explain recent U.S. export growth?," Journal of International Economics, 2014, 94 (2), 311-325.

_, Joseph Kaboski, and Virgiliu Midrigan, "The Great Trade Collapse of 2008-09: An Inventory Adjustment?," IMF Economic Review, 2010, 58, 254-294.

_ , _, and _, "Inventories, lumpy trade, and large devaluations," American Economic Review, 2010, 100(5), 2304-2339.

_, Shafaat Y Khan, Armen Khederlarian, Kim J Ruhl, and Joseph B Steinberg, "Trade-Policy Dynamics: Evidence from 60 Years of U.S.-China Trade," Working Paper 29122, National Bureau of Economic Research August 2021.

Baker, Scott R., Stephanie Johnson, and Lorenz Kueng, "Shopping for Lower Sales Tax Rates," American Economic Journal: Macroeconomics, July 2021, 13 (3), 209-50.

Baldwin, Richard, "Hysteresis in Trade," MIT mimeo prepared for 1986 NBER Summer Institute, April 1986, 1986.

_ and Paul Krugman, "Persistent Trade Effects of Large Exchange Rate Shocks," The Quarterly Journal of Economics, 1989, 104 (4), 635-654.

Bekes, Gabor, Lionel Fontagne, Balazs Murakozy, and Vincent Vicard, "Shipment Frequency of exporters and demand uncertainty: An inventory management approach," Review of World Economics, 2017, 153, 779-807.

Bernanke, Ben S., "Irreversibility, Uncertainty, and Cyclical Investment," Quarterly Journal of Economics, 1983, 98(1), 85-106.

Bianconi, Marcelo, Federico Esposito, and Marco Sammon, "Trade policy uncertainty and stock returns," Journal of International Money and Finance, 2021, 119.

Blum, Bernardo, Sebastian Claro, Kunal Dasgupta, and Ignatius Horstmann, "Inventory Management, Product Quality, and Cross-Country Income Differences," American Economic Journal: Macroeconomics, 2019, 11(1).

Caldara, Dario, Matteo Iacoviello, Patrick Molligo, Andrea Prestipino, and Andrea Raffo, "The economic effects of trade policy uncertainty," Journal of Monetary Economics, 2020, 109, 38-59.

Charnavoki, Valery, "Retail sales of durable goods, inventories and imports after large devaluations," Journal of Economic Dynamics and Control, 2019, 108 (C). 
Crowley, Meredith, Ning Meng, and Huasheng Song, "Tariff scares: Trade policy uncertainty and foreign market entry by Chinese firms," Journal of International Economics, 2018, 114, 96-115.

Das, Sanghamitra, Mark J. Roberts, and James R. Tybout, "Market entry costs, producer heterogeneity, and export dynamics," Econometrica, 2007, 75 (3), 837-873.

Dixit, Avinash, "Entry and Exit Decisions under Uncertainty," Journal of Political Economy, 1989, 97(3), 620-38.

Feenstra, Robert C., John Romalis, and Peter K. Schott, "U.S. Imports, Exports, and Tariff Data, 1989-2001," Working Paper 9387, National Bureau of Economic Research 2002.

Feng, Ling, Zhiyuan Li, and Deborah Swenson, "Trade Policy Uncertainty and Exports: Evidence from China's WTO Accession," Journal of International Economics, 2017, $106,20-36$.

Graziano, Alejandro, Kyle Handley, and Nuno Limao, "Brexit uncertainty and trade disintegration," The Economic Journal, 2020, 131 (635), 1150-1185.

Greenland, Andrew, Mihai Ion, John Lopresti, and Peter Schott, "Using Equity Market Reactions to Infer Exposure to Trade Liberalization," Working Paper, 2021.

Handley, Kyle and Nuno Limao, "Trade Investment under Policy Uncertainty: Theory and Firm Evidence," American Economic Journal: Policy, 2014.

_ and _, "Policy uncertainty, trade, and welfare: Theory and evidence for China and the United States," American Economic Review, 2017, 107(9), 2731-2783.

Hummels, David and Georg Schaur, "Time as a Trade Barrier," American Economic Review, 2013, 103(7), 2935-2959.

Kellogg, Ryan, "The Effect of Uncertainty on Investment: Evidence from Texas Oil Drilling," American Economic Review, 2014, 104(6), 1698-1734.

Khan, Shafaat Yar and Armen Khederlarian, "How does trade respond to anticipated tariff changes? Evidence from NAFTA," Journal of International Economics, 2021, 133 (C).

Kropf, Andreas and Philip Saure, "Fixed Cost per Shipment," Journal of International Economics, 2014, 92, 166-184.

Novy, Dennis and Alan M. Taylor, "Trade and Uncertainty," Review of Economics and Statistics, 2020, 102(4), 749-765.

Pierce, Justin and Peter Schott, "The surprisingly swift decline of US manufacturing employment," American Economic Journal, 2016, 106(7), 1632-1662. 
Pindyck, Robert S., "Irreversibility, Uncertainty, and Investment," Journal of Economic Literature, 1991, 29(3), 1110-48.

Roberts, Mark J. and James R. Tybout, "The Decision to Export in Colombia: An Empirical Model of Entry with Sunk Costs," American Economic Review, 1997, 87(4), $545-64$.

Ruhl, Kim, "Trade dynamics under policy uncertainty," American Journal of Agricultural Economics: Papers and Proceedings, 2011, 93 (2), 450-456.

Ruhl, Kim J. and Jonathan L. Willis, "New Exporter Dynamics," International Economic Review, 2017, 58 (3), 703-726.

Steinberg, Joseph, "Brexit and the macroeconomic impact of trade policy uncertainty," Journal of International Economics, 2019, 117, 175-195. 
Table 1: Moments and Parameters for Experiments Section 2

\begin{tabular}{llcc}
\hline & & Value & Source \\
\hline (a) Parameter & & \\
$\sigma \quad$ Demand elasticity & 4 & Standard \\
$\beta$ & Annual discount factor & 0.97 & U.S. Real interest rate in 90s \\
$f \quad$ Ordering cost (rel. median revenues) & 0.095 & Alessandria et al. (2010b) \\
$\sigma_{d}$ & Variance demand shocks & $0.8^{2}$ & Alessandria et al. (2010b) \\
$\delta$ & Annual depreciation rate & $30 \%$ & Alessandria et al. (2010b) \\
& & & \\
(b) Moments & & \\
& & & \\
& HH Index & 0.32 & \\
Median inventory-sales & 3.64 months & \\
\hline
\end{tabular}

Note: Real interest rate measured as 10-year Treasury Rate minus observed CPI inflation. 
Table 2: Seasonal Effect of TPU - Alternative Reference Trade Flows

\begin{tabular}{|c|c|c|c|c|c|c|c|}
\hline Dep. Var. $\ln \left(v_{m-2: m}^{i j g t} / v_{m-7: m-5}^{i j g t}\right)$ & (1) & $(2)$ & $(3)$ & (4) & $(5)$ & (6) & $(7)$ \\
\hline U.S. Imports RoW & $\checkmark$ & & & $\checkmark$ & & $\checkmark$ & $\checkmark$ \\
\hline E.U. Imports China & $\checkmark$ & & $\checkmark$ & & $\checkmark$ & & $\checkmark$ \\
\hline $2001-2007$ & $\checkmark$ & $\checkmark$ & & & $\checkmark$ & $\checkmark$ & \\
\hline \multicolumn{8}{|c|}{$\mathbb{1}\left\{m=m^{\prime}\right\} \mathbb{1}\{i=U . S.\} \mathbb{1}\{j=C h i n a\} \mathbb{1}\{t<2001\} X_{g}$} \\
\hline Jan & $\begin{array}{c}-0.27^{* * *} \\
(0.08)\end{array}$ & $\begin{array}{c}-0.21^{* * *} \\
(0.08)\end{array}$ & $\begin{array}{c}-0.50^{* * *} \\
(0.10)\end{array}$ & $\begin{array}{c}-0.33^{* * *} \\
(0.09)\end{array}$ & $\begin{array}{c}-0.30^{* * *} \\
(0.10)\end{array}$ & $\begin{array}{c}-0.26^{* * *} \\
(0.09)\end{array}$ & $\begin{array}{c}-0.33^{* * *} \\
(0.09)\end{array}$ \\
\hline Feb & $\begin{array}{c}-0.25^{* * *} \\
(0.08)\end{array}$ & $\begin{array}{c}-0.19^{* *} \\
(0.08)\end{array}$ & $\begin{array}{c}-0.52^{* * *} \\
(0.09)\end{array}$ & $\begin{array}{c}-0.33^{* * *} \\
(0.08)\end{array}$ & $\begin{array}{c}-0.32^{* * *} \\
(0.10)\end{array}$ & $\begin{array}{c}-0.19^{* *} \\
(0.09)\end{array}$ & $\begin{array}{c}-0.33^{* * *} \\
(0.08)\end{array}$ \\
\hline Mar & $\begin{array}{l}-0.13 \\
(0.09)\end{array}$ & $\begin{array}{l}-0.06 \\
(0.09)\end{array}$ & $\begin{array}{c}-0.37^{* * *} \\
(0.09)\end{array}$ & $\begin{array}{c}-0.27^{* * *} \\
(0.09)\end{array}$ & $\begin{array}{c}-0.23^{* *} \\
(0.10)\end{array}$ & $\begin{array}{l}-0.07 \\
(0.09)\end{array}$ & $\begin{array}{c}-0.27^{* * *} \\
(0.09)\end{array}$ \\
\hline Apr & $\begin{array}{c}0.04 \\
(0.09)\end{array}$ & $\begin{array}{c}0.10 \\
(0.09)\end{array}$ & $\begin{array}{l}-0.15 \\
(0.10)\end{array}$ & $\begin{array}{c}-0.11 \\
(0.09)\end{array}$ & $\begin{array}{l}-0.07 \\
(0.11)\end{array}$ & $\begin{array}{c}0.12 \\
(0.09)\end{array}$ & $\begin{array}{l}-0.11 \\
(0.09)\end{array}$ \\
\hline May & $\begin{array}{l}0.21^{* *} \\
(0.09)\end{array}$ & $\begin{array}{c}0.24^{* * *} \\
(0.08)\end{array}$ & $\begin{array}{c}0.09 \\
(0.10)\end{array}$ & $\begin{array}{l}0.18^{* *} \\
(0.09)\end{array}$ & $\begin{array}{c}0.09 \\
(0.11)\end{array}$ & $\begin{array}{c}0.30^{* * *} \\
(0.09)\end{array}$ & $\begin{array}{l}0.18^{* *} \\
(0.09)\end{array}$ \\
\hline Jun & $\begin{array}{c}0.31^{* * *} \\
(0.08)\end{array}$ & $\begin{array}{c}0.31^{* * *} \\
(0.08)\end{array}$ & $\begin{array}{c}0.35^{* * *} \\
(0.10)\end{array}$ & $\begin{array}{c}0.33^{* * *} \\
(0.09)\end{array}$ & $\begin{array}{c}0.28^{* * *} \\
(0.10)\end{array}$ & $\begin{array}{c}0.34^{* * *} \\
(0.08)\end{array}$ & $\begin{array}{c}0.33^{* * *} \\
(0.09)\end{array}$ \\
\hline Jul & $\begin{array}{c}0.24^{* * *} \\
(0.08)\end{array}$ & $\begin{array}{c}0.23^{* * *} \\
(0.08)\end{array}$ & $\begin{array}{c}0.42^{* * *} \\
(0.08)\end{array}$ & $\begin{array}{c}0.26^{* * *} \\
(0.08)\end{array}$ & $\begin{array}{c}0.30^{* * *} \\
(0.10)\end{array}$ & $\begin{array}{l}0.20^{* *} \\
(0.08)\end{array}$ & $\begin{array}{c}0.26^{* * *} \\
(0.08)\end{array}$ \\
\hline Aug & $\begin{array}{l}0.16^{* *} \\
(0.08)\end{array}$ & $\begin{array}{c}0.10 \\
(0.08)\end{array}$ & $\begin{array}{c}0.50^{* * *} \\
(0.09)\end{array}$ & $\begin{array}{c}0.27^{* * *} \\
(0.08)\end{array}$ & $\begin{array}{c}0.32^{* * *} \\
(0.10)\end{array}$ & $\begin{array}{c}0.07 \\
(0.09)\end{array}$ & $\begin{array}{c}0.27^{* * *} \\
(0.08)\end{array}$ \\
\hline Sep & $\begin{array}{l}-0.01 \\
(0.09)\end{array}$ & $\begin{array}{l}-0.01 \\
(0.09)\end{array}$ & $\begin{array}{c}0.25^{* * *} \\
(0.09)\end{array}$ & $\begin{array}{c}0.23^{* * *} \\
(0.08)\end{array}$ & $\begin{array}{c}0.07 \\
(0.11)\end{array}$ & $\begin{array}{l}-0.06 \\
(0.09)\end{array}$ & $\begin{array}{c}0.23^{* * *} \\
(0.08)\end{array}$ \\
\hline Oct & $\begin{array}{l}-0.10 \\
(0.09)\end{array}$ & $\begin{array}{c}-0.08 \\
(0.09)\end{array}$ & $\begin{array}{c}0.17^{*} \\
(0.09)\end{array}$ & $\begin{array}{l}0.22^{* *} \\
(0.09)\end{array}$ & $\begin{array}{l}-0.01 \\
(0.11)\end{array}$ & $\begin{array}{c}-0.17^{*} \\
(0.09)\end{array}$ & $\begin{array}{l}0.22^{* *} \\
(0.09)\end{array}$ \\
\hline Nov & $\begin{array}{c}-0.25^{* * *} \\
(0.09)\end{array}$ & $\begin{array}{c}-0.19^{* *} \\
(0.08)\end{array}$ & $\begin{array}{c}-0.07 \\
(0.10)\end{array}$ & $\begin{array}{l}-0.05 \\
(0.09)\end{array}$ & $\begin{array}{c}-0.14 \\
(0.10)\end{array}$ & $\begin{array}{c}-0.35^{* * *} \\
(0.09)\end{array}$ & $\begin{array}{l}-0.05 \\
(0.09)\end{array}$ \\
\hline Dec & $\begin{array}{c}-0.31^{* * *} \\
(0.08)\end{array}$ & $\begin{array}{c}-0.27^{* * *} \\
(0.08)\end{array}$ & $\begin{array}{c}-0.21^{* *} \\
(0.09)\end{array}$ & $\begin{array}{c}-0.25^{* * *} \\
(0.09)\end{array}$ & $\begin{array}{c}-0.23^{* *} \\
(0.10)\end{array}$ & $\begin{array}{c}-0.39^{* * *} \\
(0.09)\end{array}$ & $\begin{array}{c}-0.25^{* * *} \\
(0.09)\end{array}$ \\
\hline Peak to trough & $\begin{array}{c}0.62^{* * *} \\
(0.15)\end{array}$ & $\begin{array}{c}0.58^{* * *} \\
(0.14)\end{array}$ & $\begin{array}{c}1.02^{* * *} \\
(0.16)\end{array}$ & $\begin{array}{c}0.65^{* * *} \\
(0.16)\end{array}$ & $\begin{array}{c}0.64^{* * *} \\
(0.17)\end{array}$ & $\begin{array}{c}0.73^{* * *} \\
(0.15)\end{array}$ & $\begin{array}{c}0.65^{* * *} \\
(0.16)\end{array}$ \\
\hline Industry-Specific FEs & ijgm,gtm & $g m$ & gtm & gtm & gtm,jgm & gtm,igm & jgtm \\
\hline Aggregate FEs & ijtm & $t m$ & $j t m$ & itm & $j t m$ & itm & ijtm \\
\hline Observations & $1,131,369$ & 370,784 & 394,980 & 424,840 & 705,358 & 740,090 & 424,840 \\
\hline Adjusted $R^{2}$ & 0.287 & 0.262 & 0.190 & 0.203 & 0.245 & 0.279 & 0.203 \\
\hline
\end{tabular}

Note: All estimates are obtained by adapting the baseline estimation equation 5 to the included trade flows, indicated at the top of the Table. The corresponding fixed effects that fully saturate the model are indicated at the bottom of the Table. Standard errors in parentheses are clustered at the industry level, ${ }^{*} p<0.05$, ${ }^{* *} p<0.01,{ }^{* * *} p<0.001$. 
Table 3: Seasonal Effect of TPU - Alternative Dependent and Independent Variables

\begin{tabular}{|c|c|c|c|c|c|c|}
\hline & $\begin{array}{c}\text { Baseline } \\
\text { (1) }\end{array}$ & $\begin{array}{l}\text { Mid } \\
\text { Point } \\
(2)\end{array}$ & $\begin{array}{c}v_{m}^{i j g t} \\
(3)\end{array}$ & $\begin{array}{l}\text { Log Annual } \\
\text { Share } \\
(4)\end{array}$ & $\begin{array}{c}\text { Annual Share } \\
\text { (PPML) } \\
(5)\end{array}$ & $\begin{array}{l}\text { Log Annual Share } \\
\text { w/Moving Average } \\
(6)\end{array}$ \\
\hline \multicolumn{7}{|c|}{$\mathbb{1}\left\{m=m^{\prime}\right\} \mathbb{1}\{i=U . S.\} \mathbb{1}\{j=C h i n a\} \mathbb{1}\{t<2001\} X_{g}$} \\
\hline Jan & $\begin{array}{c}-0.27^{* * *} \\
(0.08)\end{array}$ & $\begin{array}{c}-0.29^{* * *} \\
(0.07)\end{array}$ & $\begin{array}{l}-0.12 \\
(0.08)\end{array}$ & $\begin{array}{l}-0.11 \\
(0.08)\end{array}$ & $\begin{array}{c}-0.23^{* * *} \\
(0.08)\end{array}$ & $\begin{array}{c}-0.17^{* * *} \\
(0.06)\end{array}$ \\
\hline Feb & $\begin{array}{c}-0.25^{* * *} \\
(0.08)\end{array}$ & $\begin{array}{c}-0.25^{* * *} \\
(0.07)\end{array}$ & $\begin{array}{l}-0.08 \\
(0.08)\end{array}$ & $\begin{array}{l}-0.07 \\
(0.08)\end{array}$ & $\begin{array}{c}0.06 \\
(0.09)\end{array}$ & $\begin{array}{c}-0.15^{* *} \\
(0.06)\end{array}$ \\
\hline Mar & $\begin{array}{c}-0.13 \\
(0.09)\end{array}$ & $\begin{array}{c}-0.19^{* * *} \\
(0.07)\end{array}$ & $\begin{array}{l}-0.01 \\
(0.08)\end{array}$ & $\begin{array}{c}0.01 \\
(0.08)\end{array}$ & $\begin{array}{c}0.06 \\
(0.09)\end{array}$ & $\begin{array}{c}-0.04 \\
(0.06)\end{array}$ \\
\hline Apr & $\begin{array}{c}0.04 \\
(0.09)\end{array}$ & $\begin{array}{l}-0.01 \\
(0.07)\end{array}$ & $\begin{array}{c}0.08 \\
(0.08)\end{array}$ & $\begin{array}{c}0.09 \\
(0.08)\end{array}$ & $\begin{array}{l}0.16^{*} \\
(0.09)\end{array}$ & $\begin{array}{c}0.09 \\
(0.06)\end{array}$ \\
\hline May & $\begin{array}{l}0.21^{* *} \\
(0.09)\end{array}$ & $\begin{array}{l}0.16^{* *} \\
(0.07)\end{array}$ & $\begin{array}{c}0.02 \\
(0.07)\end{array}$ & $\begin{array}{c}0.03 \\
(0.07)\end{array}$ & $\begin{array}{c}0.11 \\
(0.08)\end{array}$ & $\begin{array}{c}0.12^{*} \\
(0.06)\end{array}$ \\
\hline Jun & $\begin{array}{c}0.31^{* * *} \\
(0.08)\end{array}$ & $\begin{array}{c}0.26^{* * *} \\
(0.07)\end{array}$ & $\begin{array}{c}0.04 \\
(0.07)\end{array}$ & $\begin{array}{c}0.05 \\
(0.07)\end{array}$ & $\begin{array}{c}0.09 \\
(0.08)\end{array}$ & $\begin{array}{c}0.15^{* * *} \\
(0.05)\end{array}$ \\
\hline Jul & $\begin{array}{c}0.24^{* * *} \\
(0.08)\end{array}$ & $\begin{array}{c}0.20^{* * *} \\
(0.07)\end{array}$ & $\begin{array}{l}0.17^{* *} \\
(0.07)\end{array}$ & $\begin{array}{l}0.18^{* *} \\
(0.07)\end{array}$ & $\begin{array}{l}0.15^{* *} \\
(0.07)\end{array}$ & $\begin{array}{l}0.13^{* *} \\
(0.05)\end{array}$ \\
\hline Aug & $\begin{array}{l}0.16^{* *} \\
(0.08)\end{array}$ & $\begin{array}{c}0.12^{*} \\
(0.07)\end{array}$ & $\begin{array}{l}-0.04 \\
(0.07)\end{array}$ & $\begin{array}{l}-0.02 \\
(0.07)\end{array}$ & $\begin{array}{c}0.03 \\
(0.08)\end{array}$ & $\begin{array}{l}0.09^{*} \\
(0.05)\end{array}$ \\
\hline Sep & $\begin{array}{l}-0.01 \\
(0.09)\end{array}$ & $\begin{array}{c}0.04 \\
(0.07)\end{array}$ & $\begin{array}{c}0.02 \\
(0.07)\end{array}$ & $\begin{array}{c}0.04 \\
(0.07)\end{array}$ & $\begin{array}{c}0.11 \\
(0.08)\end{array}$ & $\begin{array}{l}0.09^{*} \\
(0.05)\end{array}$ \\
\hline Oct & $\begin{array}{l}-0.10 \\
(0.09)\end{array}$ & $\begin{array}{l}-0.04 \\
(0.07)\end{array}$ & $\begin{array}{l}-0.13 \\
(0.08)\end{array}$ & $\begin{array}{l}-0.11 \\
(0.08)\end{array}$ & $\begin{array}{l}-0.02 \\
(0.08)\end{array}$ & $\begin{array}{c}0.02 \\
(0.05)\end{array}$ \\
\hline Nov & $\begin{array}{c}-0.25^{* * *} \\
(0.09)\end{array}$ & $\begin{array}{c}-0.17^{* *} \\
(0.08)\end{array}$ & $\begin{array}{c}-0.36^{* * *} \\
(0.09)\end{array}$ & $\begin{array}{c}-0.35^{* * *} \\
(0.09)\end{array}$ & $\begin{array}{c}-0.25^{* * *} \\
(0.08)\end{array}$ & $\begin{array}{c}-0.07 \\
(0.06)\end{array}$ \\
\hline Dec & $\begin{array}{c}-0.31^{* * *} \\
(0.08)\end{array}$ & $\begin{array}{c}-0.28^{* * *} \\
(0.07)\end{array}$ & $\begin{array}{c}-0.21^{* * *} \\
(0.08)\end{array}$ & $\begin{array}{c}-0.20^{* *} \\
(0.08)\end{array}$ & $\begin{array}{c}-0.26^{* * *} \\
(0.08)\end{array}$ & $\begin{array}{c}-0.22^{* * *} \\
(0.06)\end{array}$ \\
\hline Peak to trough & $\begin{array}{c}0.62^{* * *} \\
(0.15)\end{array}$ & $\begin{array}{c}0.54^{* * *} \\
(0.13)\end{array}$ & $\begin{array}{c}0.53^{* * *} \\
(0.11)\end{array}$ & $\begin{array}{c}0.53^{* * *} \\
(0.11)\end{array}$ & $\begin{array}{l}0.41^{\text {** }} \\
(0.12)\end{array}$ & $\begin{array}{c}0.37^{* * *} \\
(0.09)\end{array}$ \\
\hline Observations & $1,131,369$ & $1,182,433$ & $1,085,060$ & $1,085,060$ & $1,179,351$ & $1,157,251$ \\
\hline Adjusted $R^{2}$ & 0.287 & 0.245 & 0.937 & 0.204 & & 0.238 \\
\hline
\end{tabular}

Note: All estimates are obtained using (5) and include the fixed effects $\gamma_{i j t m}, \gamma_{i j g m}, \gamma_{g t m}$. The peak to trough elasticity is estimated as $\max _{m}\left\{\hat{\beta}_{m}\right\}-\min _{m}\left\{\hat{\beta}_{m}\right\}$. Standard errors in parentheses are clustered at the industry level, ${ }^{*} p<0.05,{ }^{* *} p<0.01,{ }^{* * *} p<0.001$. 
Table 4: Seasonal Effect of TPU - Alternative Samples

\begin{tabular}{|c|c|c|c|c|c|}
\hline & $\begin{array}{c}\text { Baseline } \\
\text { (1) }\end{array}$ & $\begin{array}{c}\text { Balanced } \\
1991-2007 \\
(2)\end{array}$ & $\begin{array}{c}\text { Full } \\
\text { Sample } \\
(3)\end{array}$ & $\begin{array}{c}\text { Developed } \\
\text { Countries } \\
(4)\end{array}$ & $\begin{array}{c}\text { Developing } \\
\text { Countries } \\
(5)\end{array}$ \\
\hline \multicolumn{6}{|c|}{$\mathbb{1}\left\{m=m^{\prime}\right\} \mathbb{1}\{i=U . S.\} \mathbb{1}\{j=$ China $\} \mathbb{1}\{t<2001\} X_{g}$} \\
\hline Jan & $\begin{array}{c}-0.27^{* * *} \\
(0.08)\end{array}$ & $\begin{array}{c}-0.28^{* * *} \\
(0.08)\end{array}$ & $\begin{array}{c}-0.23^{* * *} \\
(0.08)\end{array}$ & $\begin{array}{c}-0.22^{* *} \\
(0.09)\end{array}$ & $\begin{array}{c}-0.31^{* * *} \\
(0.08)\end{array}$ \\
\hline Feb & $\begin{array}{c}-0.24^{* * *} \\
(0.08)\end{array}$ & $\begin{array}{c}-0.25^{* * *} \\
(0.08)\end{array}$ & $\begin{array}{c}-0.20^{* *} \\
(0.08)\end{array}$ & $\begin{array}{c}-0.23^{* * *} \\
(0.08)\end{array}$ & $\begin{array}{c}-0.28^{* * *} \\
(0.08)\end{array}$ \\
\hline Mar & $\begin{array}{l}-0.13 \\
(0.09)\end{array}$ & $\begin{array}{l}-0.13 \\
(0.09)\end{array}$ & $\begin{array}{l}-0.14^{*} \\
(0.08)\end{array}$ & $\begin{array}{c}-0.14 \\
(0.09)\end{array}$ & $\begin{array}{c}-0.13 \\
(0.09)\end{array}$ \\
\hline Apr & $\begin{array}{c}0.02 \\
(0.09)\end{array}$ & $\begin{array}{c}0.02 \\
(0.09)\end{array}$ & $\begin{array}{l}-0.05 \\
(0.09)\end{array}$ & $\begin{array}{c}0.01 \\
(0.10)\end{array}$ & $\begin{array}{c}0.01 \\
(0.09)\end{array}$ \\
\hline May & $\begin{array}{l}0.18^{* *} \\
(0.09)\end{array}$ & $\begin{array}{c}0.17^{*} \\
(0.09)\end{array}$ & $\begin{array}{l}0.16^{*} \\
(0.09)\end{array}$ & $\begin{array}{c}0.14 \\
(0.10)\end{array}$ & $\begin{array}{l}0.18^{* *} \\
(0.09)\end{array}$ \\
\hline Jun & $\begin{array}{c}0.31^{* * *} \\
(0.08)\end{array}$ & $\begin{array}{c}0.30^{* * *} \\
(0.08)\end{array}$ & $\begin{array}{l}0.20^{* *} \\
(0.08)\end{array}$ & $\begin{array}{c}0.25^{* * *} \\
(0.09)\end{array}$ & $\begin{array}{c}0.30^{* * *} \\
(0.08)\end{array}$ \\
\hline Jul & $\begin{array}{c}0.24^{* * *} \\
(0.08)\end{array}$ & $\begin{array}{c}0.25^{* * *} \\
(0.08)\end{array}$ & $\begin{array}{l}0.16^{* *} \\
(0.08)\end{array}$ & $\begin{array}{c}0.24^{* * *} \\
(0.09)\end{array}$ & $\begin{array}{c}0.25^{* * *} \\
(0.08)\end{array}$ \\
\hline Aug & $\begin{array}{l}0.16^{* *} \\
(0.08)\end{array}$ & $\begin{array}{c}0.16^{*} \\
(0.08)\end{array}$ & $\begin{array}{c}0.12 \\
(0.08)\end{array}$ & $\begin{array}{l}0.16^{*} \\
(0.09)\end{array}$ & $\begin{array}{l}0.19^{* *} \\
(0.08)\end{array}$ \\
\hline Sep & $\begin{array}{l}-0.01 \\
(0.09)\end{array}$ & $\begin{array}{l}-0.01 \\
(0.09)\end{array}$ & $\begin{array}{l}-0.03 \\
(0.08)\end{array}$ & $\begin{array}{l}-0.03 \\
(0.09)\end{array}$ & $\begin{array}{l}-0.00 \\
(0.09)\end{array}$ \\
\hline Oct & $\begin{array}{l}-0.10 \\
(0.09)\end{array}$ & $\begin{array}{c}-0.10 \\
(0.09)\end{array}$ & $\begin{array}{c}-0.12 \\
(0.08)\end{array}$ & $\begin{array}{l}-0.08 \\
(0.09)\end{array}$ & $\begin{array}{l}-0.10 \\
(0.09)\end{array}$ \\
\hline Nov & $\begin{array}{c}-0.25^{* * *} \\
(0.09)\end{array}$ & $\begin{array}{c}-0.23^{* * *} \\
(0.09)\end{array}$ & $\begin{array}{c}-0.19^{* *} \\
(0.08)\end{array}$ & $\begin{array}{c}-0.17^{*} \\
(0.09)\end{array}$ & $\begin{array}{c}-0.25^{* * *} \\
(0.09)\end{array}$ \\
\hline Dec & $\begin{array}{c}-0.31^{* * *} \\
(0.08)\end{array}$ & $\begin{array}{c}-0.31^{* * *} \\
(0.08)\end{array}$ & $\begin{array}{c}-0.30^{* * *} \\
(0.08)\end{array}$ & $\begin{array}{c}-0.23^{* * *} \\
(0.09)\end{array}$ & $\begin{array}{c}-0.34^{* * *} \\
(0.09)\end{array}$ \\
\hline Peak to trough & $\begin{array}{c}0.62^{* * *} \\
(0.15)\end{array}$ & $\begin{array}{c}0.60^{* * *} \\
(0.15)\end{array}$ & $\begin{array}{c}0.50^{* * *} \\
(0.14)\end{array}$ & $\begin{array}{l}0.47^{* *} \\
(0.15)\end{array}$ & $\begin{array}{l}0.64^{* *} \\
(0.15)\end{array}$ \\
\hline Observations & $1,131,369$ & $1,104,231$ & $1,794,796$ & $1,124,645$ & $1,125,351$ \\
\hline Adjusted $R^{2}$ & 0.287 & 0.292 & 0.214 & 0.267 & 0.272 \\
\hline
\end{tabular}

Note: All estimates are obtained using (5) and include the fixed effects $\gamma_{i j t m}, \gamma_{i j g m}, \gamma_{g t m}$. The peak to trough elasticity is estimated as $\max _{m}\left\{\hat{\beta}_{m}\right\}-\min _{m}\left\{\hat{\beta}_{m}\right\}$. Standard errors in parentheses are clustered at the industry level, ${ }^{*} p<0.05,{ }^{* *} p<0.01,{ }^{* * *} p<0.001$. 
Table 5: Baseline Calibration

\begin{tabular}{|c|c|c|c|}
\hline Parameter & Meaning & Value & Target/Source \\
\hline \multicolumn{4}{|c|}{ (a) Common Parameters } \\
\hline$\sigma_{d}$ & Variance demand shocks & 1 & Ad-hoc (sensitivity) \\
\hline$\sigma$ & Demand elasticity & 2.7 & Khan and Khederlarian (2021) \\
\hline $\bar{d}_{g}$ & Average demand & 0 & No demand effect \\
\hline$\beta$ & Annual discount factor & 0.97 & U.S. real interest rate $1990 \mathrm{~s}$ \\
\hline$T_{g}=\left\{0, \tilde{X}_{g}\right\}$ & Maximum NNTR gap & Varies & Pierce and Schott (2016) \\
\hline \multicolumn{4}{|c|}{ (b) Parameters calibrated to match inverse $H H$ index distribution and peak to trough response } \\
\hline$\delta_{g}$ & Depreciation rate (monthly) & See Fig. 9a & Distribution of inverse HH index \\
\hline$f_{g}=\alpha_{0}\left(1+\delta_{g}\right)^{\alpha_{1}}$ & Ordering Cost & See Fig. 9b & \\
\hline$\alpha_{0}$ & Ordering cost if $\delta=0$ & 1.1 & Peak to trough high storability \\
\hline$\alpha_{1}$ & Correlation $f$ and $\delta$ & -51 & Peak to trough low storability \\
\hline$\hat{\pi}$ & Probability MFN to NNTR & $3.22 \%$ & Average peak to trough \\
\hline \multicolumn{4}{|c|}{ (c) Target Moments } \\
\hline & Distribution inverse $\mathrm{HH}$ index & See Fig. 10 & Data - Figure 7 \\
\hline & Average peak to trough in (7) & 0.62 & 0.62 - Estimate section 3.4 \\
\hline & Constant peak to trough in $(8)$ & 1.42 & 1.29 - Estimate section 3.6 \\
\hline & Interaction storability peak to trough in (8) & -0.25 & -0.26 - Estimate section 3.6 \\
\hline
\end{tabular}

Note: A high (low) storable good is defined by the $10^{\text {th }}\left(90^{\text {th }}\right)$ percentile of the inverse HH index. The peak to trough elasticity is calculated as $\max _{m}\left\{\beta_{m}\right\}-\min _{m}\left\{\beta_{m}\right\}$. 


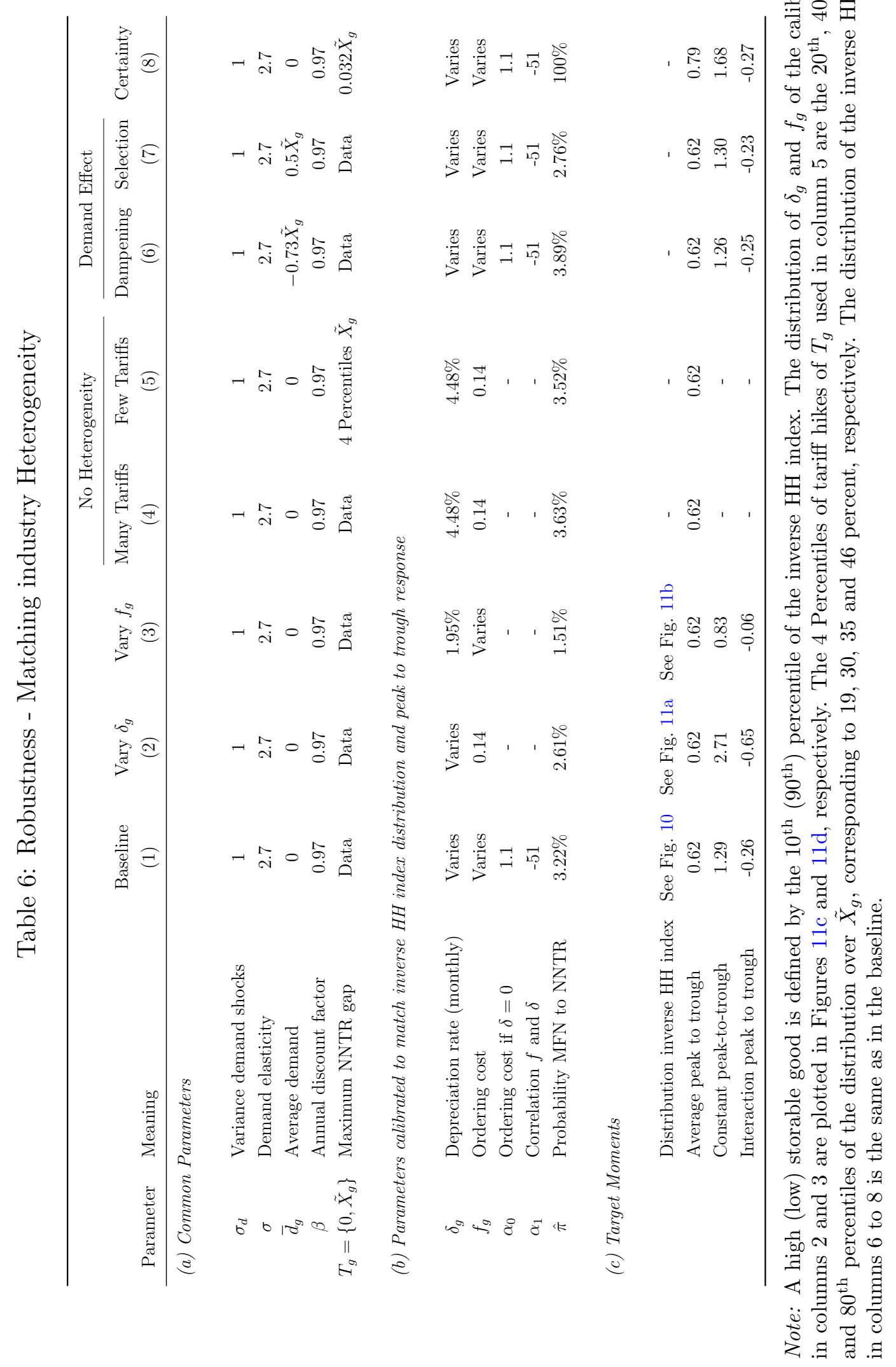


Table 7: Robustness - Sensitivity to Common Parameter Values

\begin{tabular}{|c|c|c|c|c|c|c|}
\hline \multirow[b]{2}{*}{ Parameter } & \multirow[b]{2}{*}{ Meaning } & \multirow{2}{*}{$\frac{\text { Column } 5 \text { Table } 6}{(1)}$} & \multicolumn{2}{|c|}{ Sensitivity $\sigma_{\nu}$} & \multicolumn{2}{|c|}{ Sensitivity $\sigma$} \\
\hline & & & $(2)$ & $(3)$ & $(4)$ & (5) \\
\hline \multicolumn{7}{|c|}{ (a) Common Parameters } \\
\hline$\sigma_{d}$ & Variance demand shocks & 1 & $0.8^{2}$ & $1.2^{2}$ & 1 & 1 \\
\hline$\sigma$ & Demand elasticity & 2.7 & 2.7 & 2.7 & 1.5 & 4 \\
\hline $\bar{d}_{g}$ & Average demand & 0 & 0 & 0 & 0 & 0 \\
\hline$\beta$ & Annual discount factor & 0.97 & 0.97 & 0.97 & 0.97 & 0.97 \\
\hline$T_{g}=\left\{0, \tilde{X}_{g}\right\}$ & Maximum NNTR gap & 4 Percentiles $\tilde{X}_{g}$ & 4 Percentiles $\tilde{X}_{g}$ & 4 Percentiles $\tilde{X}_{g}$ & 4 Percentiles $\tilde{X}_{g}$ & 4 Percentiles $\tilde{X}_{g}$ \\
\hline$\delta_{g}$ & Depreciation rate (monthly) & $4.48 \%$ & $4.48 \%$ & $4.48 \%$ & $4.48 \%$ & $4.48 \%$ \\
\hline$f_{g}$ & Ordering Cost & 0.14 & 0.14 & 0.14 & 0.14 & 0.14 \\
\hline \multicolumn{7}{|c|}{ (b) Parameter calibrated to match average peak to trough response } \\
\hline$\hat{\pi}$ & Probability MFN to NNTR & $3.52 \%$ & $3.57 \%$ & $3.33 \%$ & $2.93 \%$ & $4.18 \%$ \\
\hline \multicolumn{7}{|c|}{ (c) Target Moments } \\
\hline & Average peak to trough & 0.62 & 0.62 & 0.62 & 0.62 & 0.62 \\
\hline
\end{tabular}

Note: The 4 Percentiles of tariff hikes of $T_{g}$ are the $20^{\text {th }}, 40^{\text {th }}, 60^{\text {th }}$ and $80^{\text {th }}$ percentiles of the distribution over $\tilde{X}_{g}$, corresponding to $19,30,35$ and 46 percent, respectively. 
Table 8: Estimated Annual Probabilities

\begin{tabular}{lcccc}
\hline & Peak & Trough & $\max _{m}\left\{\hat{\beta}_{m t}^{T P U}\right\}$ & \\
Year $(t)$ & Month & Month & $-\min _{m}\left\{\hat{\beta}_{m t}^{T P U}\right\}$ & $\hat{\pi}$ \\
& $(1)$ & $(2)$ & $(3)$ & $(4)$ \\
\hline 1990 & Jul '90 & Feb '91 & $0.67^{*}$ & $3.48 \%$ \\
1991 & Aug '91 & Dec '92 & 0.27 & $1,40 \%$ \\
1992 & Aug '92 & Jan '93 & 0.43 & $2.23 \%$ \\
1993 & May '93 & Dec '94 & $0.95^{* * *}$ & $4.93 \%$ \\
1994 & Jul '94 & Dec '95 & $1.07^{* * *}$ & $5.60 \%$ \\
1995 & Jun '95 & Dec '96 & $1.32^{* * *}$ & $6.86 \%$ \\
1996 & Jun '96 & Dec '97 & $1.08^{* * *}$ & $5.61 \%$ \\
1997 & Jun '97 & Jan '98 & $0.69^{* *}$ & $3.58 \%$ \\
1998 & Jun '98 & Dec '99 & 0.12 & $0.62 \%$ \\
1999 & Aug '99 & Mar '00 & 0.35 & $1.82 \%$ \\
2000 & Jun '00 & Dec '00 & $0.62^{* *}$ & $3.22 \%$ \\
\hline Average & & & & \\
$1990-2000$ & & & $0.69^{* * *}$ & $3.58 \%$ \\
\hline
\end{tabular}

Note: The coefficients in column 3 are the peak to trough estimates obtained by (9), i.e. $\left\{\max _{m}\left\{\hat{\beta}_{m t}\right\}-\right.$ $\left.\min _{m}\left\{\hat{\beta}_{m t}\right\}\right\}_{t=1990}^{2000}$. Column $4(\hat{\pi})$ are the annual probabilities estimated from the model using the approach described in the main text. In the bottom row we report the average over the annual estimates. ${ }^{*} p<0.10$, ${ }^{* *} p<0.05,{ }^{* * *} p<0.01$. 
Table 9: Decomposing Level Effect from Pure Uncertainty

\begin{tabular}{lccccc}
\hline & $\begin{array}{c}\text { Standardized } \\
\tilde{v}_{m_{\text {res }}-2: m_{\text {res }}} / \tilde{v}_{m_{\text {res }}-7: m_{\text {res }-5}:}\end{array}$ & $\begin{array}{c}\text { Level } \\
(1)\end{array}$ & $\begin{array}{c}\text { Level } \\
(2)\end{array}$ & $\begin{array}{c}\text { Standardized } \\
(3)\end{array}$ & $\begin{array}{c}\text { level } \\
(5)\end{array}$ \\
\hline Standardized $\mathbb{E}\left(\tilde{\pi}_{n} \tilde{X}_{n}\right)$ & $0.59^{* * *}$ & & & $0.59^{* * *}$ & \\
Standardized $\operatorname{Var}\left(X_{n}\right)$ & & & & $-0.27^{* *}$ & \\
$\mathbb{E}\left(\tilde{\pi}_{n} \tilde{X}_{n}\right)$ & & $10.17^{* * *}$ & $14.81^{* * *}$ & & $14.81^{* * *}$ \\
{$\left[\mathbb{E}\left(\tilde{\pi}_{n} \tilde{X}_{n}\right)\right]^{2}$} & & & $-22.11^{* *}$ & & $-10.92^{* * *}$ \\
$\operatorname{Var}\left(X_{n}\right)$ & & & & & $-10.33^{* * *}$ \\
\hline Oberservations & 80 & 80 & 80 & 80 & 80 \\
$R^{2}$ & 0.85 & 0.85 & 0.87 & 0.87 & 1 \\
\hline
\end{tabular}

Note: Standarized column and rows re-define each variable by deducting its mean and scaling it by its standard error. The 80 observations correspond to the simulated dataset described in section $5.2 . \mathbb{E}\left(\tilde{X}_{n} \tilde{\pi}_{n}\right)$ is the expected tariff change and $\operatorname{Var}\left(X_{n}\right)$ is the variance of each possible tariff change. ${ }^{*} p<0.10,{ }^{* *}$ $p<0.05,{ }^{* * *} p<0.01$. 
Figure 1: Import Response to Different Probabilities of a Tariff Hike

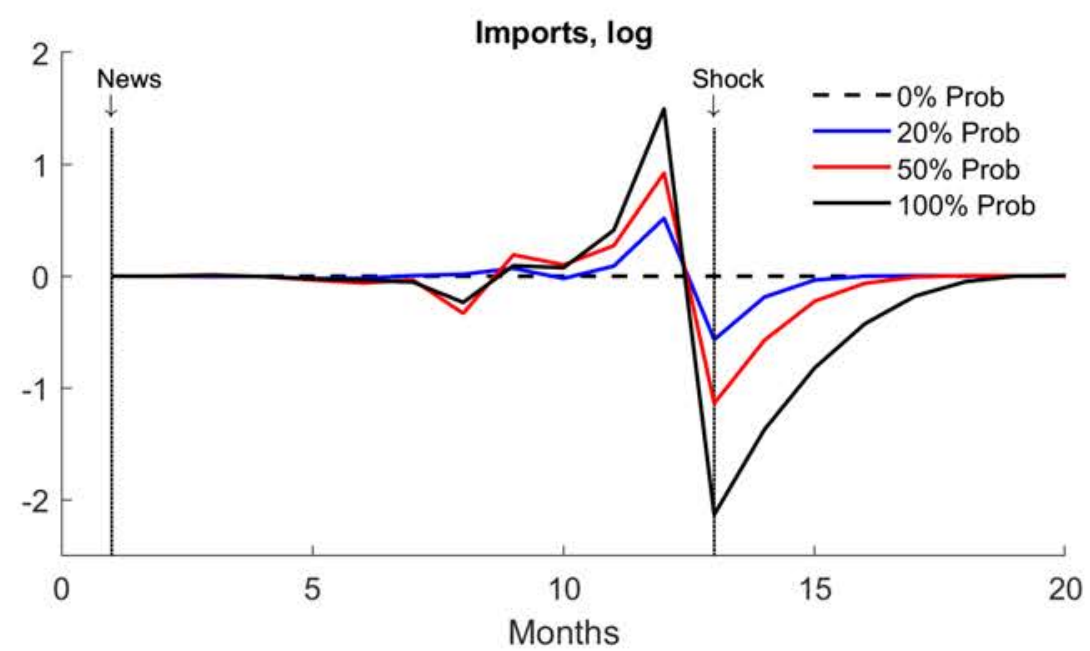

Note: This plot illustrates the anticipatory response of Imports to an uncertain change in tariff. We assign different probabilities to the event of $10 \%$ increase in tariffs 12 months ahead. The vertical dotted line denotes the time of the uncertainty resolution. In all cases, the uncertain shock does not realize.

Figure 2: Inventory Response to Different Probabilities of Tariff Hike

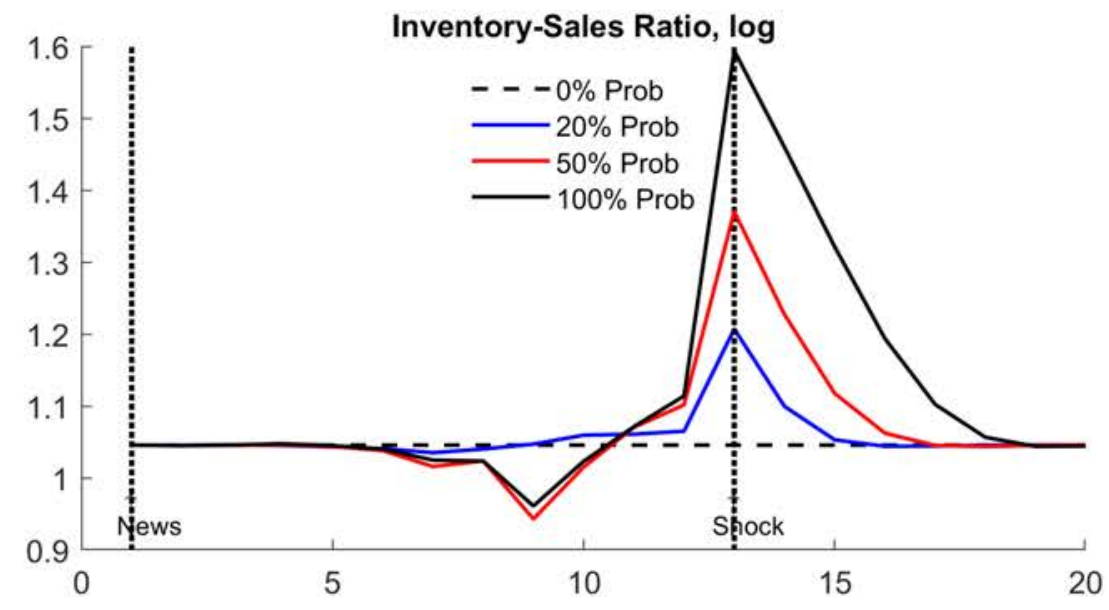

Note: This plot illustrates the anticipatory response of aggregate Inventory-Sales ratio to an uncertain change in tariff. We assign different probabilities to the event of $10 \%$ increase in tariffs 12 months ahead. The vertical dotted line denotes the time of the uncertainty resolution. In all cases, the uncertain shock does not realize. 
Figure 3: Time-Varying Ordering Cutoffs: $(\underline{s}, \bar{s})$ bands

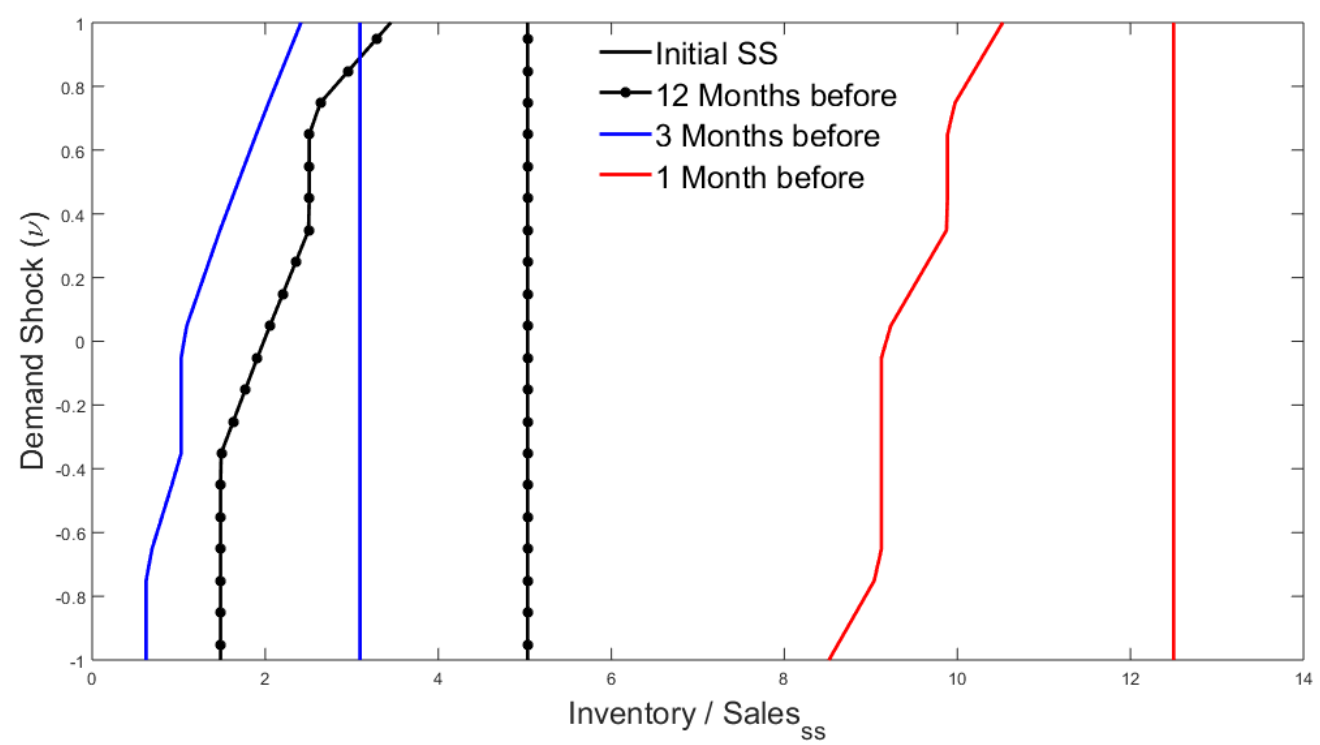

Note: This plot illustrates how a firm's ordering behavior changes as it nears the resolution of uncertainty. It plots the firm's optimal decision to order or not for the firm's state space - the contemporaneous demand shock on the $\mathrm{y}$-axis and the inventory holdings scaled by the average sales at the steady state on the $\mathrm{x}$-axis. Moving from left to right, the firm orders in the region to the left of the left line ( $\underline{s}$ (for all colors) and doesn't order when to the right of it. The right vertical line is $\bar{s}$ - beyond which the firm never goes.

Figure 4: The NNTR Gap over Time

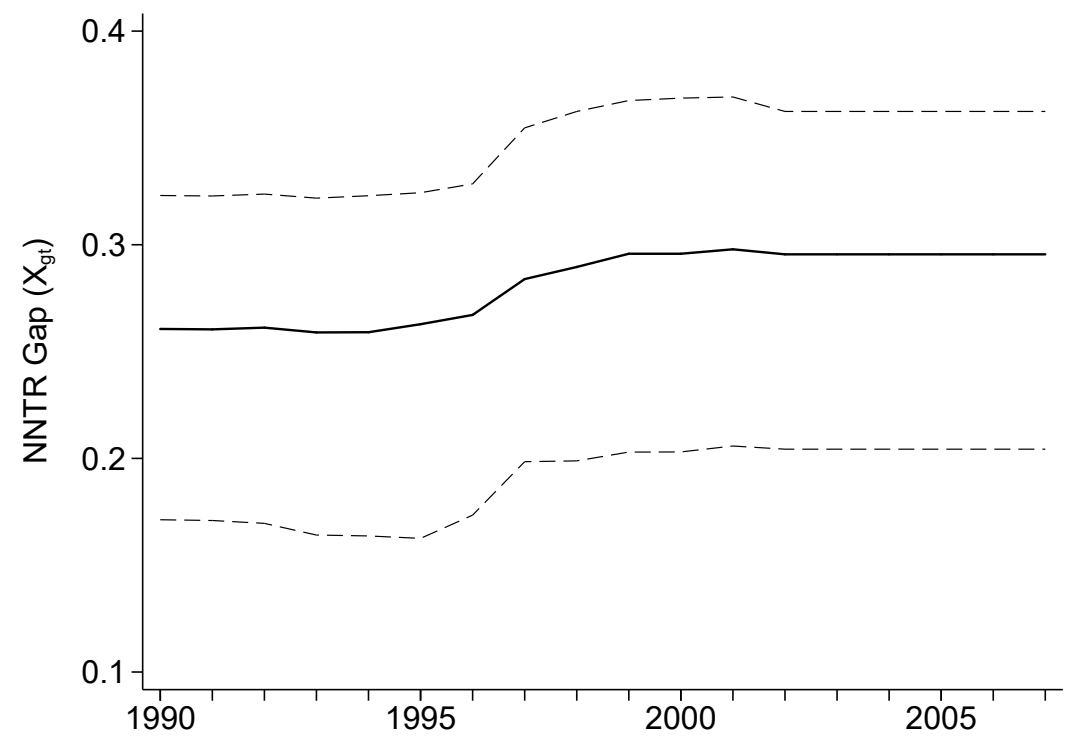

Note: This figure plots the median NNTR gap $X_{g t}$ over time, where $X_{g t} \equiv \ln \left(\left(1+\tau_{g t}^{N N T R}\right) /\left(1+\tau_{g t}^{M F N}\right)\right)$. The dashed lines are the $25^{\text {th }}$ and $75^{\text {th }}$ percentile of $X_{g t}$, respectively. 
Figure 5: Cross-Industry Variation of the NNTR Gap

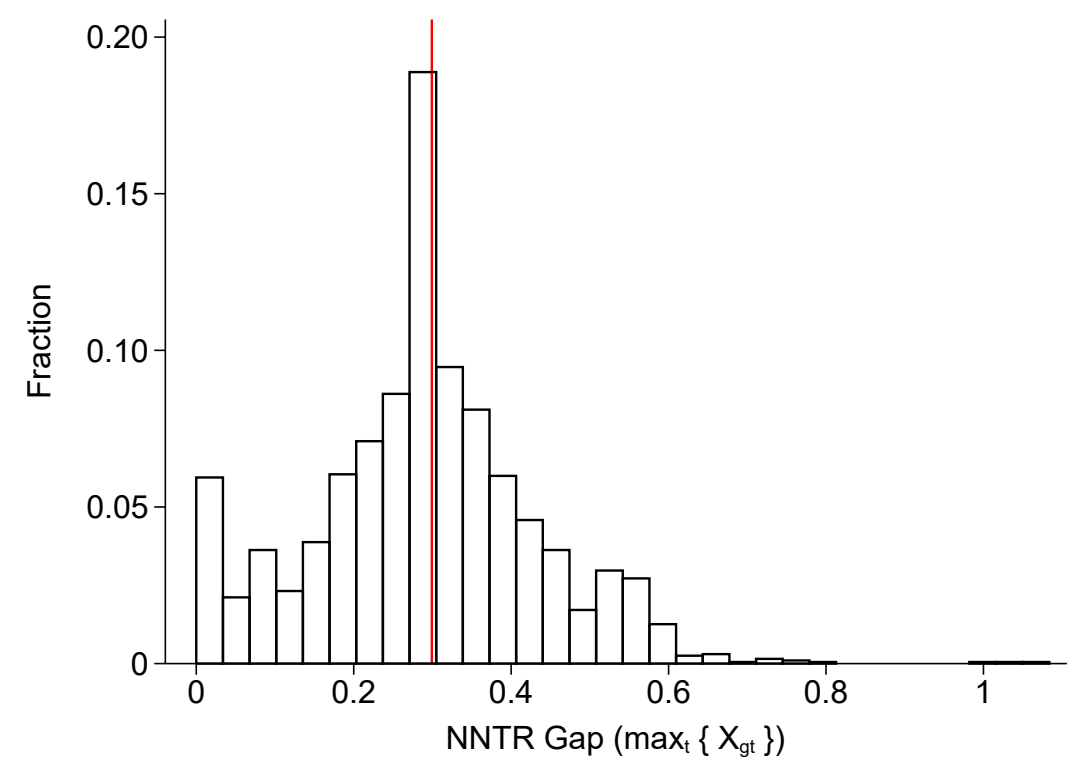

Note: This figure plots the maximum tariff risk faced by each HS-6 industry during 1991 and 2000; i.e. $X_{g} \equiv \max _{t}\left\{\ln \left(\left(1+\tau_{g t}^{N N T R}\right) /\left(1+\tau_{g t}^{M F N}\right)\right)\right\}$.

Figure 6: Seasonal Effect of TPU

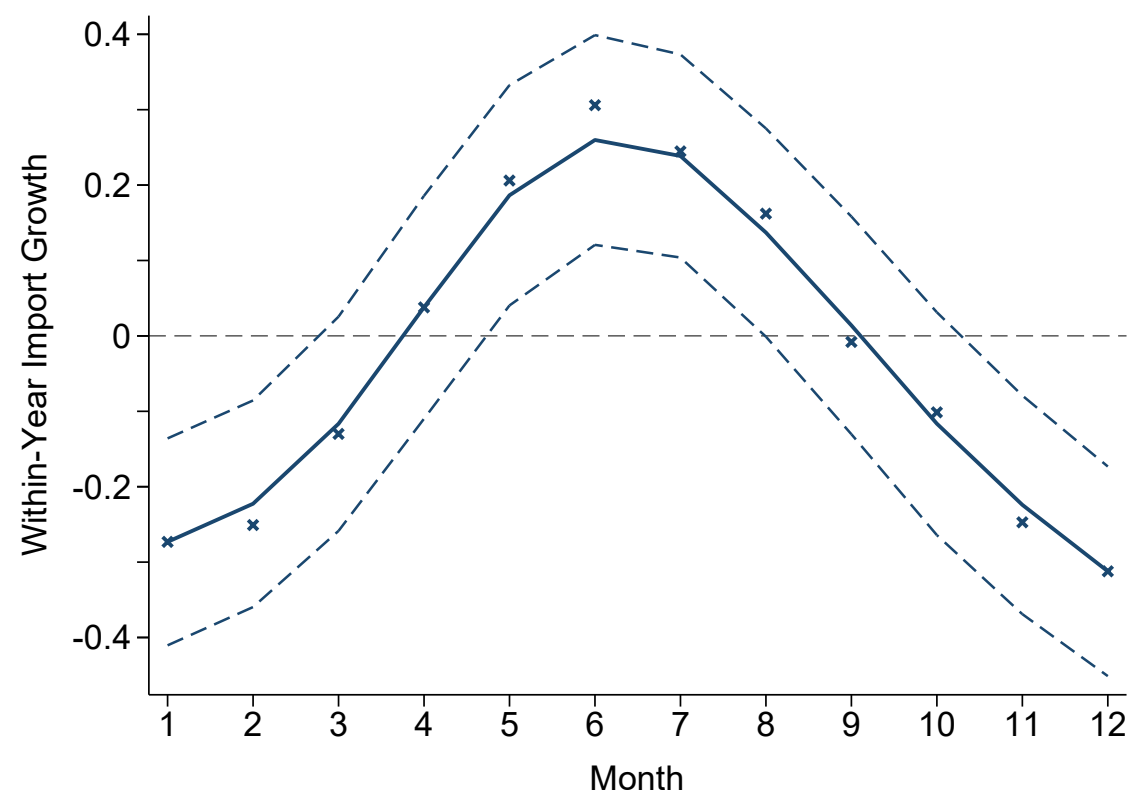

Note: Crosses are the estimates of $\left\{\hat{\beta}_{m}\right\}_{m=1}^{12}$ from (5). The corresponding point estimates are reported in column 5 of Table 2. The blue line is the locally weighted scatterplot smoother. Dashed lines are the $90 \%$ confidence interval. Standard errors are clustered at HS-6 industry level. 


\section{Figure 7: Distribution of Inverse HH Index (Storability)}

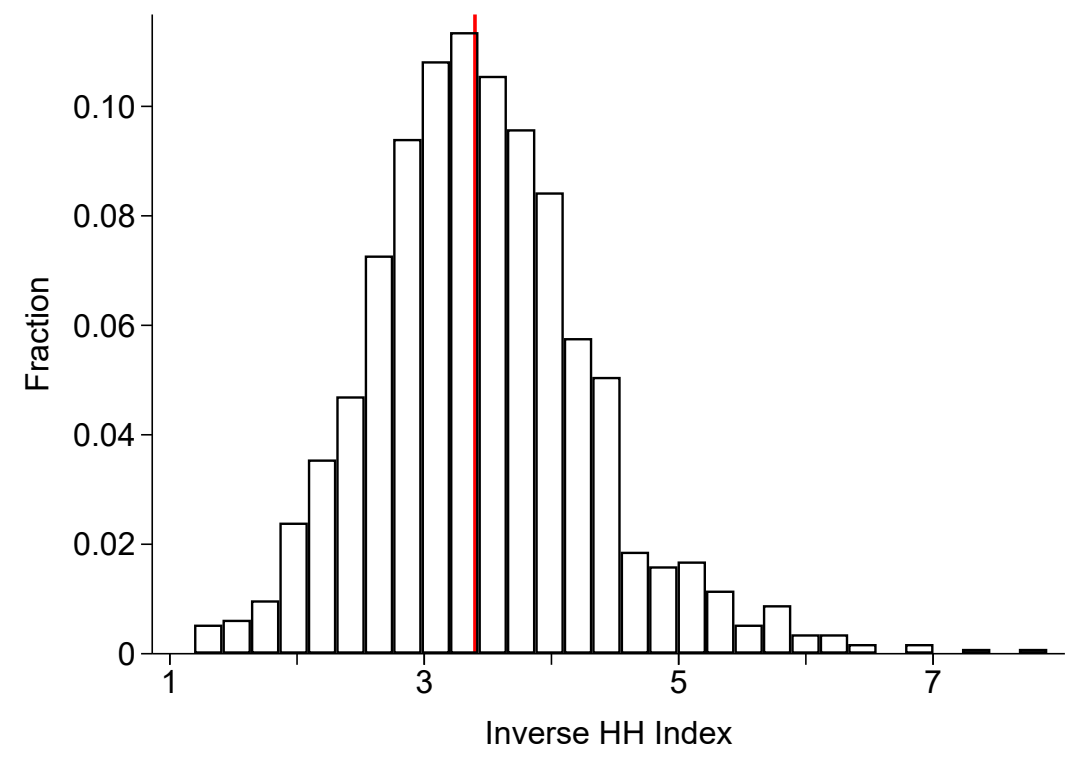

Note: This Figure plots the distribution of our measure of storability, the inverse HH index - goods that are ordered less frequently are presumably more storable. Its calculation is described in footnote 22 . The red line is the median.

Figure 8: High vs. Low Storable Good

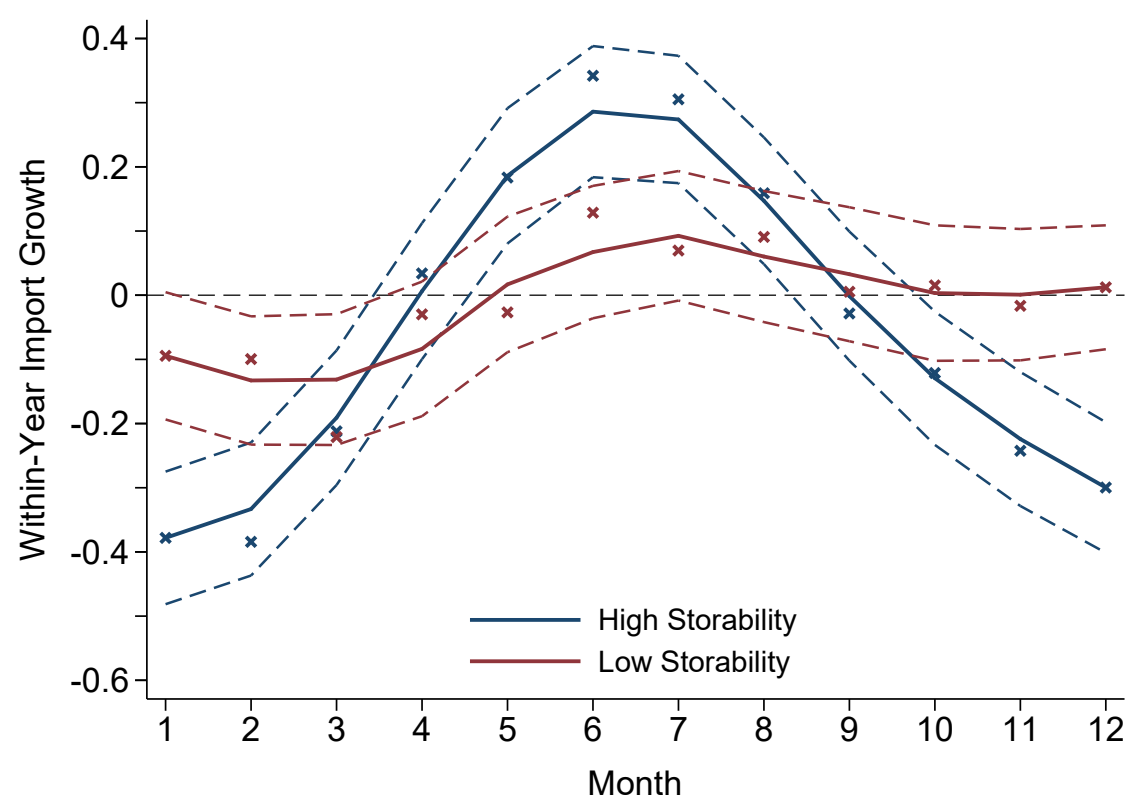

Note: Crosses are the marginal effect of $X_{g}$ from estimating (6), that is, $\left\{\hat{\beta}_{m}+\hat{\beta}_{m}^{H H} \times\left[1 / H H_{g}\right]\right\}_{m=1}^{12}$ for a high and low storable good, defined as the 10th and 90th percentile of the inverse HH distribution, respectively. The red and blue lines are the locally weighted scatterplot smoothers. Dashed lines are the $68 \%$ confidence interval or deviations of one standard error. Standard errors are clustered at HS-6 industry level. 
Figure 9: Distribution of Baseline Parameters

(a) Depreciation Rate $\left(\delta_{g}\right)$

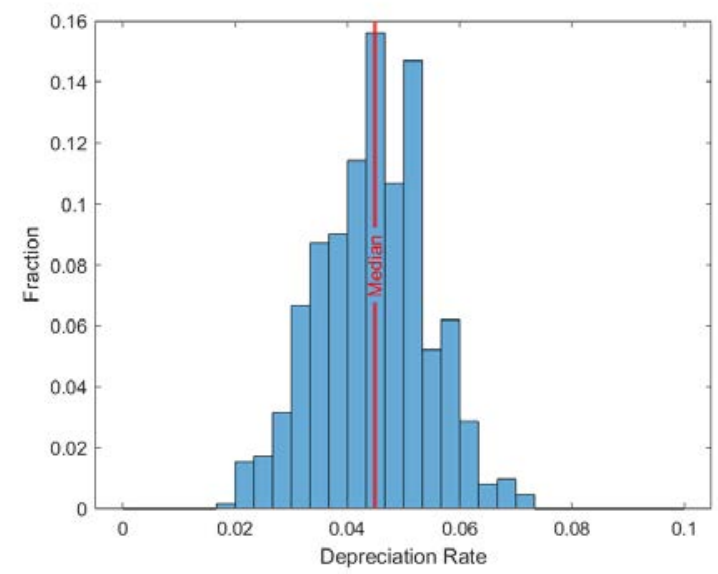

(b) Ordering Cost $\left(f_{g}\right)$

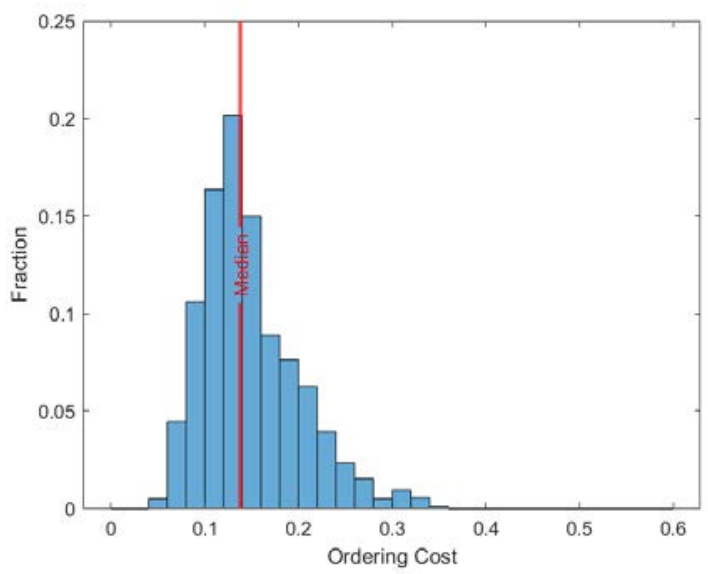

Note: The left panel plots the distribution of the calibrated depreciation rates of the 1,812 HS-6 products used in the probability estimation. The right panel plots the distribution over ordering costs. In the baseline $f_{g}=\alpha_{0}\left(1+\delta_{g}\right)^{\alpha_{1}}$ and its parameters are described in Table 5.

Figure 10: Fit of Inverse HH Index Distribution - Baseline

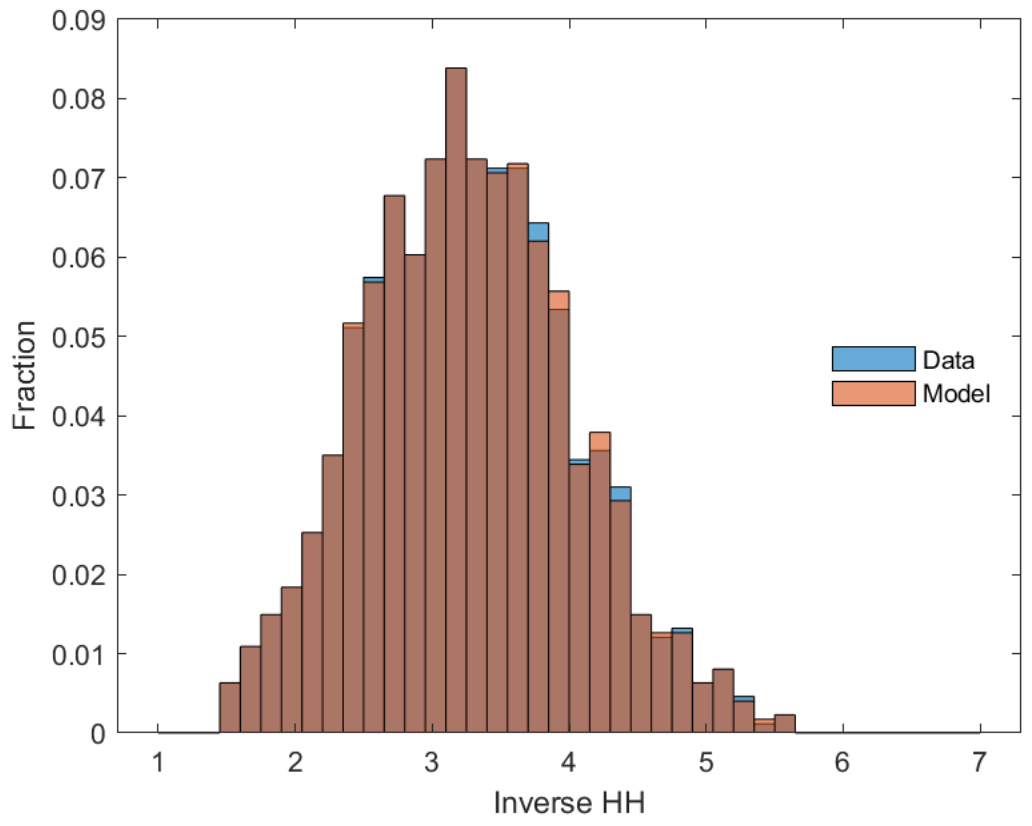

Note: This Figure plots the distribution of observed inverse HH indexes (blue) and the steady state inverse $\mathrm{HH}$ indexes under the baseline calibration described in Table 5 (orange). 
Figure 11: Alternative Calibration Approaches

(a) Fit Inverse HH under "Vary $\delta_{g} "$

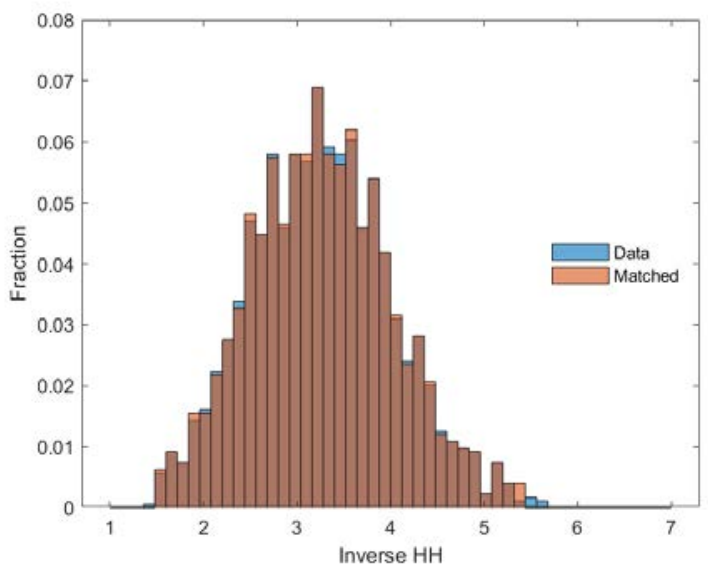

(c) Distribution $\delta_{g}$ under "Vary $\delta_{g} "$

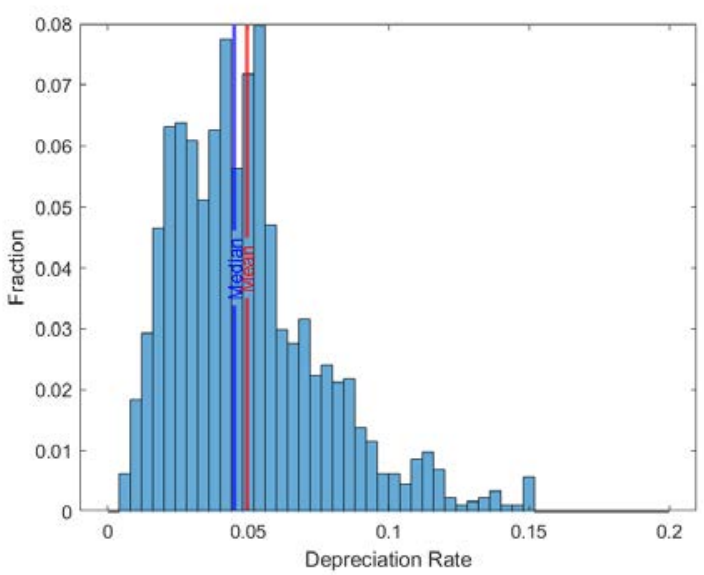

(b) Fit Inverse HH under "Vary $f_{g}$ "

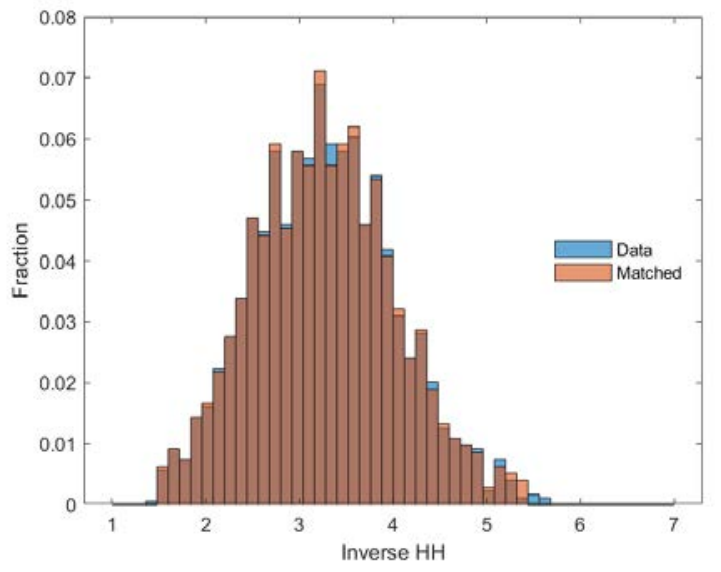

(d) Distribution $f_{g}$ under "Vary $f_{g}$ "

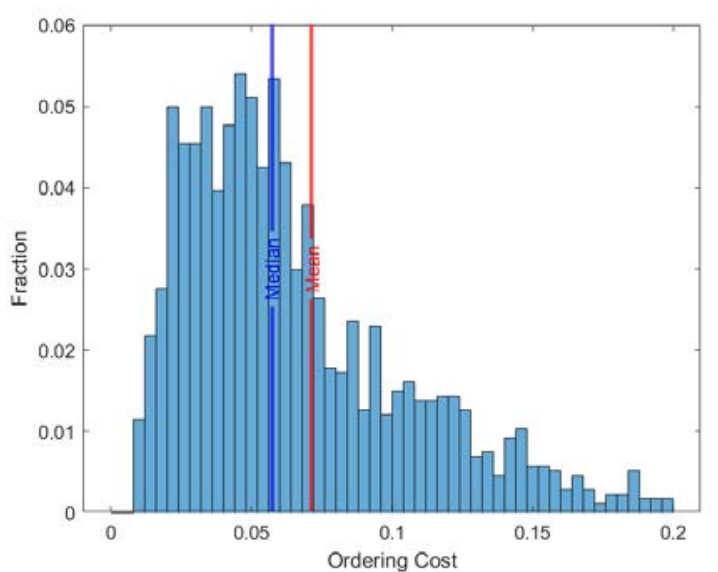

Note: Panels (a) and (c) correspond to the alternative calibration that only uses variation in $\delta_{g}$ to match the inverse HH distribution. Panel (b) and (d) correspond to the calibration that only uses $f_{g}$ to match the inverse HH distribution. Columns 2 and 3 of Table 6 report the other parameter values of these calibrations. 


\section{Figure 12: The peak to trough Elasticity and Sources of Heterogeneity}

(a) Baseline

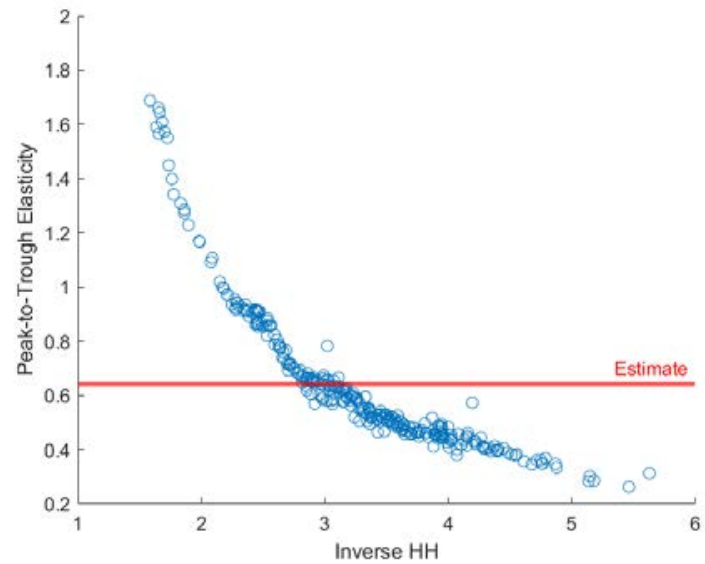

(c) Vary fixed order costs $\left(f_{g}\right)$

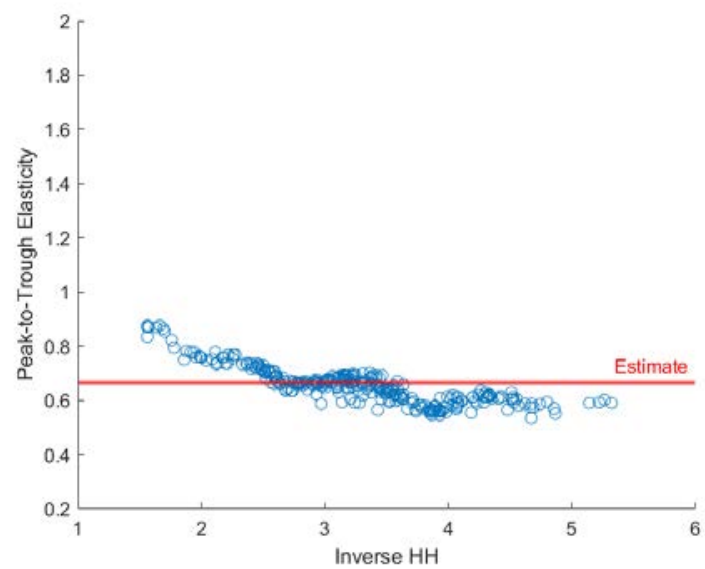

(b) Vary depreciation rate $\left(\delta_{g}\right)$

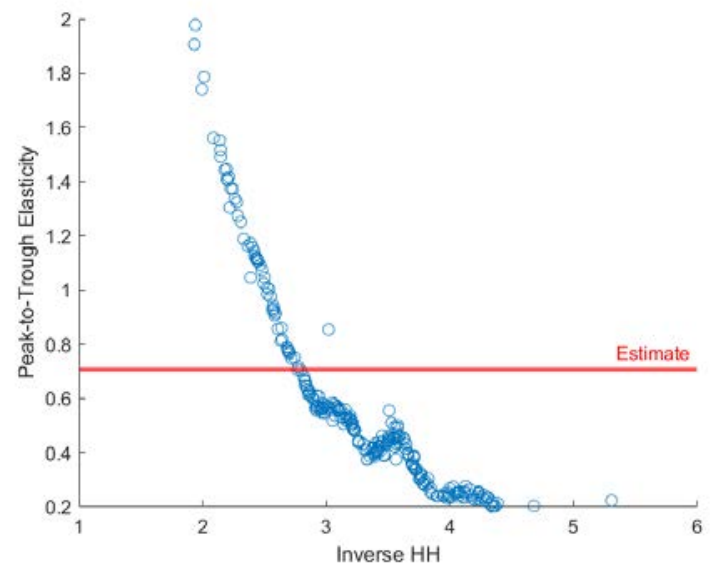

(d) No Heterogeneity

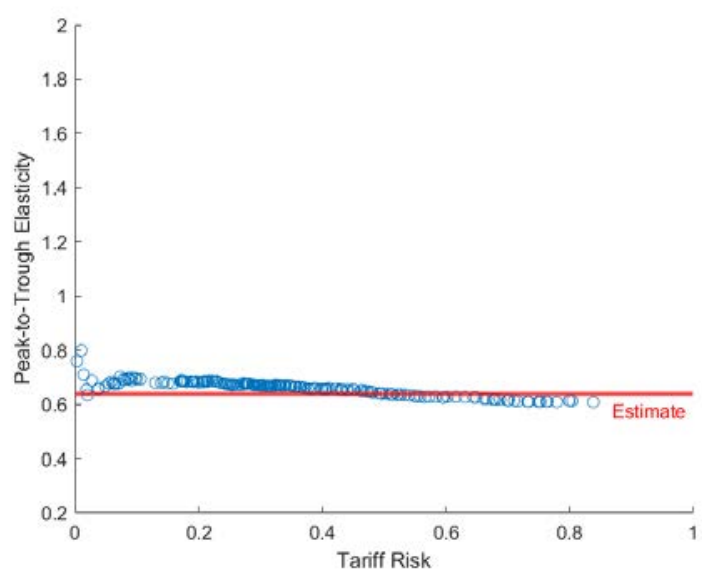

Note: All Figures plot the peak to trough elasticity, that is, $\max _{m}\left\{\beta^{s i m}\right\}-\min _{m}\left\{\beta_{m}^{s i m}\right\}$, of each $\operatorname{simulation}^{\text {. }}$ Panel A, B and C plot it against the inverse HH index (x-axis) using the simulations from the baseline calibration (Table 5), the "Vary depreciation rate $\left(\delta_{g}\right)$ " calibration, and the "Vary fixed order costs $\left(f_{g}\right)$ " calibration, respectively. Panel D plots it against the tariff gap using the calibration "No heterogeneity". These calibrations are described in columns 2, 3 and 4 of Table 6. 


\section{Figure 13: Estimated Annual Probabilities of China maintaining MFN Access}

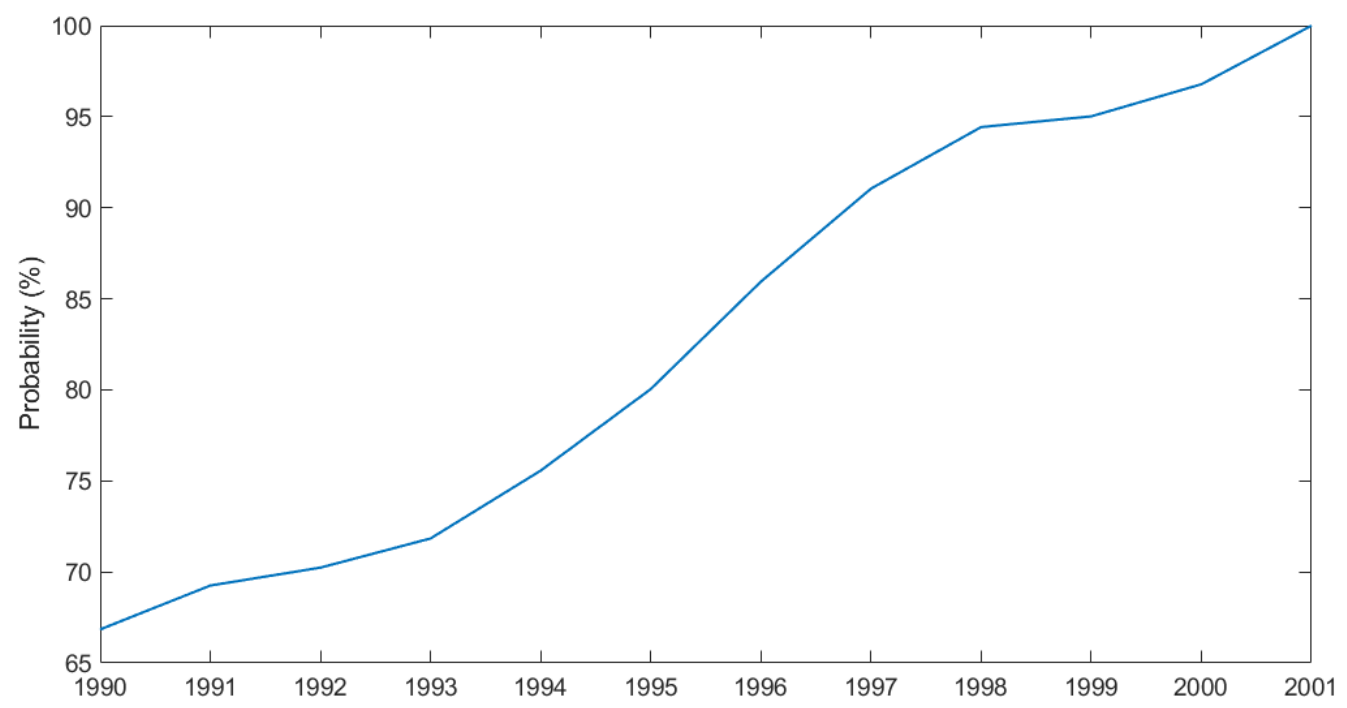

Note: On the y-axis are the model implied probabilities of China maintaining its MFN status until 2001. To obtain these we use the annual probabilities of China maintaining its MFN status $(1-\hat{\pi})$ reported in column 4 of Table 8 and compound them for the successive years until 2001. 
Figure 14: Comparison of Ordering Cutoffs: The Wait-and-See Effect

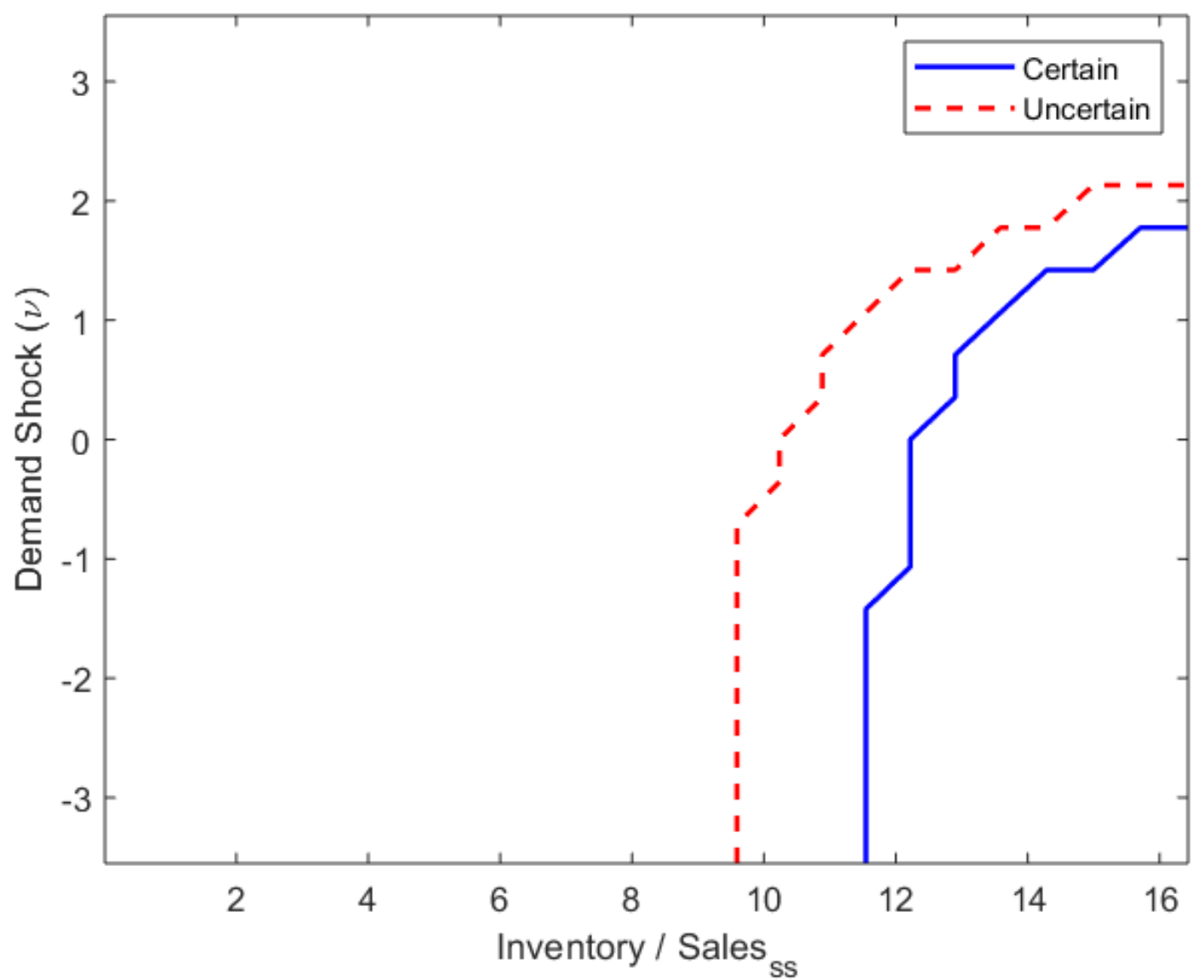

Note: The y-axis is the level of demand shock and the $\mathrm{x}$-axis are inventory holdings scaled by steady-state average sales. The area left of the lines are the ordering regions. Blue solid line corresponds to the case of a $40 \%$ tariff change with certainty. The red dashed line corresponds to the uncertain case in which tariff remain the same or increase by $80 \%$ with equal probabilities. 
Figure 15: Simulation Result with Varying Expected Tariff Change

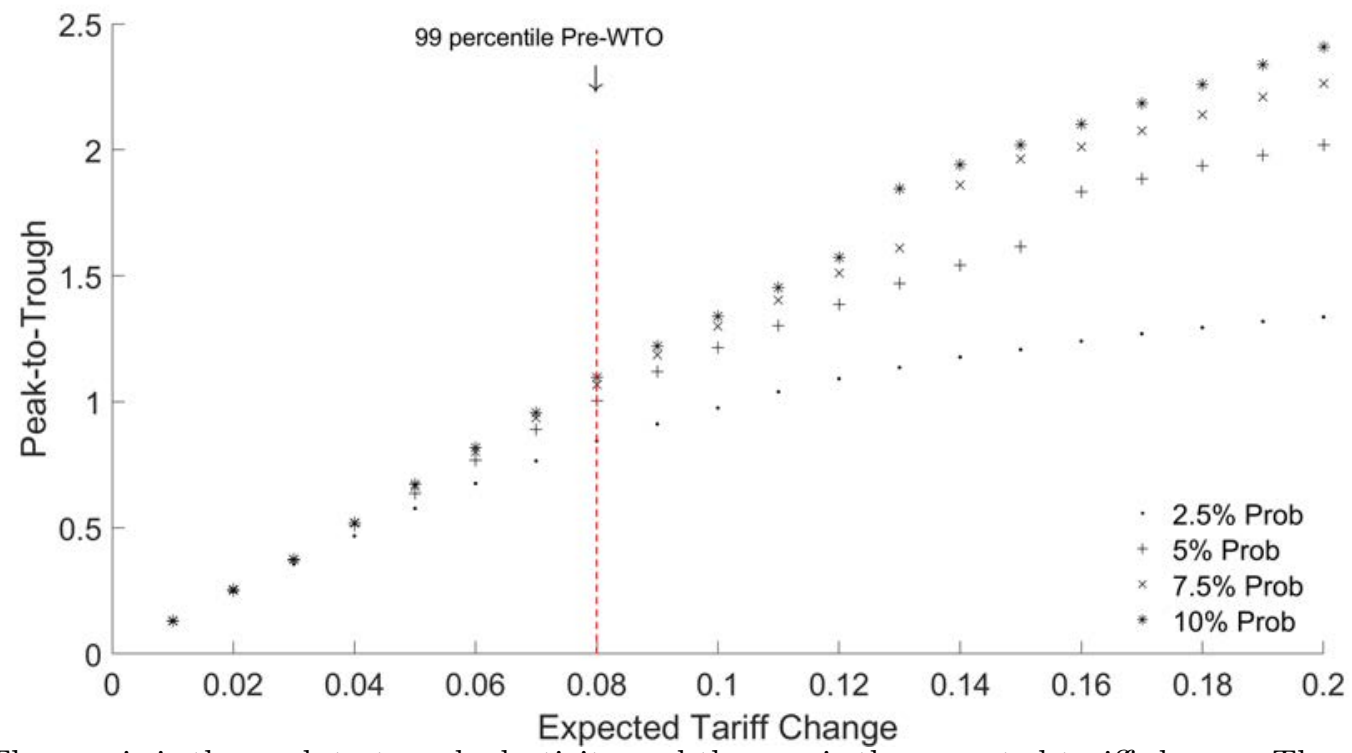

Note: The y-axis is the peak to trough elasticity and the $\mathrm{x}$-axis the expected tariff change. The dashed line is the maximum expected tariff change faced by any Chinese industry exporting to the United States. It is calculated as the maximum annual probability of non-renewal (8\%) and the 99 percentile spread (80\%).

Figure 16: Change in Entry Value and Tariff Risk

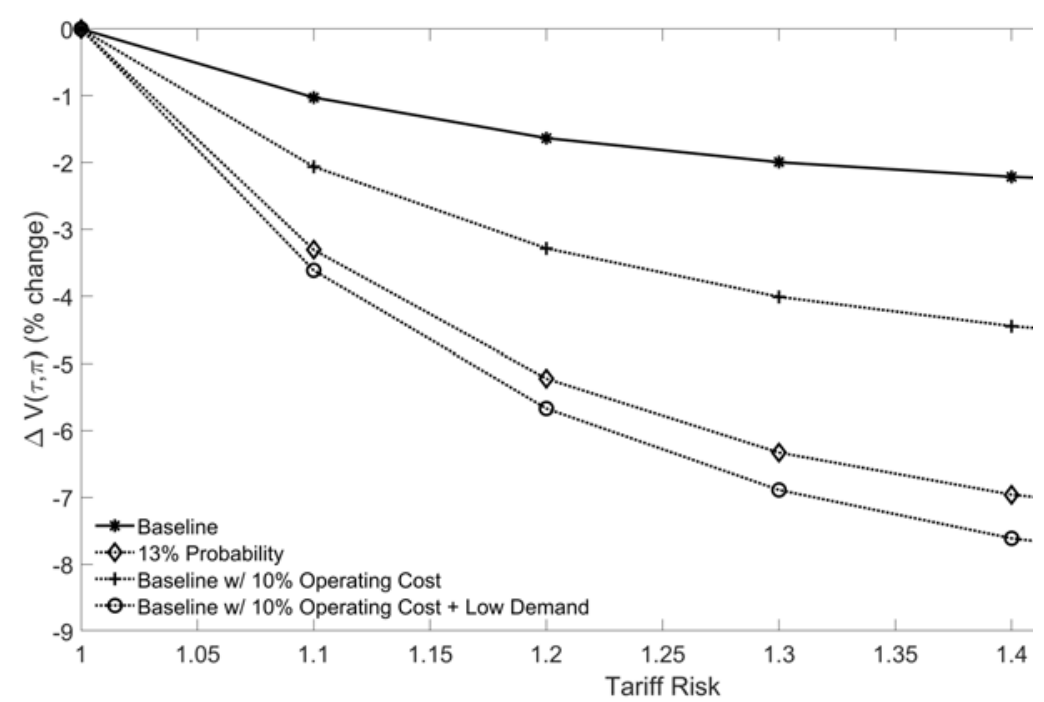

Note: This figure plots the gap in the value of entering in an uncertain industry 12 months before and after the uncertainty resolution, respectively. The loss in value is denominated in the flow value in steady state without uncertainty. The line with low demand shows the value with $25 \%$ reduction in demand. 


\section{Appendix}

\section{A Evidence from Brexit}

We now present supportive, high-level evidence that anticipatory stockpiling to trade policy influenced U.K. trade flows in the transition to Brexit. Unlike the U.S. China tariffs, the size and date of tariff changes were also uncertain. Indeed, the first two dates, March 29 and October 31 of 2019, were each delayed while in the end, the third date, December 31, 2021, was only finalized on December 24th. Each proposed date is characterized by a spike in trade followed by a collapse and then rebound.

Figure C.1 plots U.K. trade with E.U. and non-E.U. blocks in a three year window, from August 2018 to August 2021, that includes three proposed departures from the European Union. Both panels show very large spikes in trade to and from the European Union in the months preceding the proposed departures. These spikes are followed with substantial declines in the following months. The boom bust structure is not apparent for imports and exports with non-E.U. countries. The booms and busts are much larger with the final departure date than the earlier dates. Indeed the declines in UK-EU trade in these months are larger, and less persistent, than the transitory declines in trade from COVID.

\section{B Model Robustness: Signals and Early Resolution}

In our baseline we assume that the probability of non-renewal was the same in every month before the date of resolution. Here we study two alternative specifications that serve as robustness checks of our approach. First, we consider the case of an updating of the probability of non-renewal; second, we study the case of an early resolution. Both experiments illustrate that the short-lived dynamics from the $(\underline{s}, \bar{s})$ ordering model are well suited to capture the near-term risk in a fairly narrow window around expected resolution of uncertainty.

First, we introduce unanticipated signals on the MFN resolution. Specifically, we assume a larger dispersion of outcomes - namely a 15 percent of MFN reversal - and then update information on the likelihood to 6 percent, in either 1,3 or 6 periods before the resolution. Figure C.4 shows the ordering behavior looks quite similar in the three cases. Only in the case of the "Signal 1 period ahead" is the behavior slightly different. When the initial probability is 15 percent, firms start responding earlier to the possibility of a tariff hike. When the signal (from 15 percent to 6 percent probability) is received one period before the resolution, firms have already stockpiled sufficiently and decrease their orders in the last period before the resolution. Again, under our moving average growth measure these differences cancel out yielding almost identical peak growth rates. When the signal is received 3 and 6 periods 
before the resolution the ordering pattern is almost indistinguishable from the benchmark case.

Second, we allow the uncertainty to be resolved earlier than expected. In particular, firms initiate their orderings believing that tariffs might increase with a 6 percent chance after a year, but then update the likelihood to 0 percent after period 7 . As you can see in Figure C.5, there is no change in imports in period 13. Hence, our approach would imply that there was no uncertainty regarding the non-renewal of China's MFN status. 


\section{Figures}

Figure C.1: UK Trade Dynamics by Partner by Proposed Brexit Date
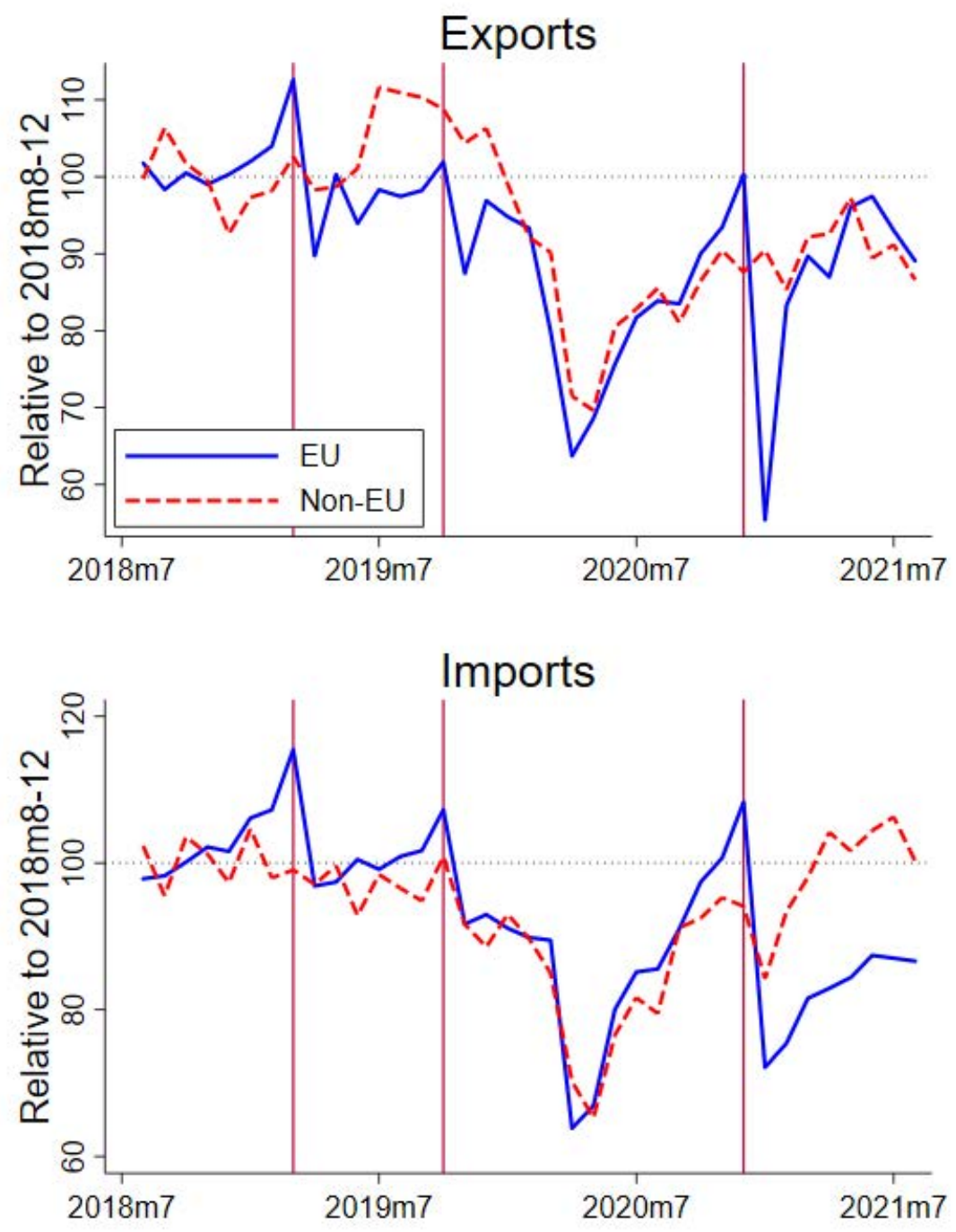

Note: Last date: 08/21, Source: UK ONS; Vertical lines denote expected and actual Brexit dates. 


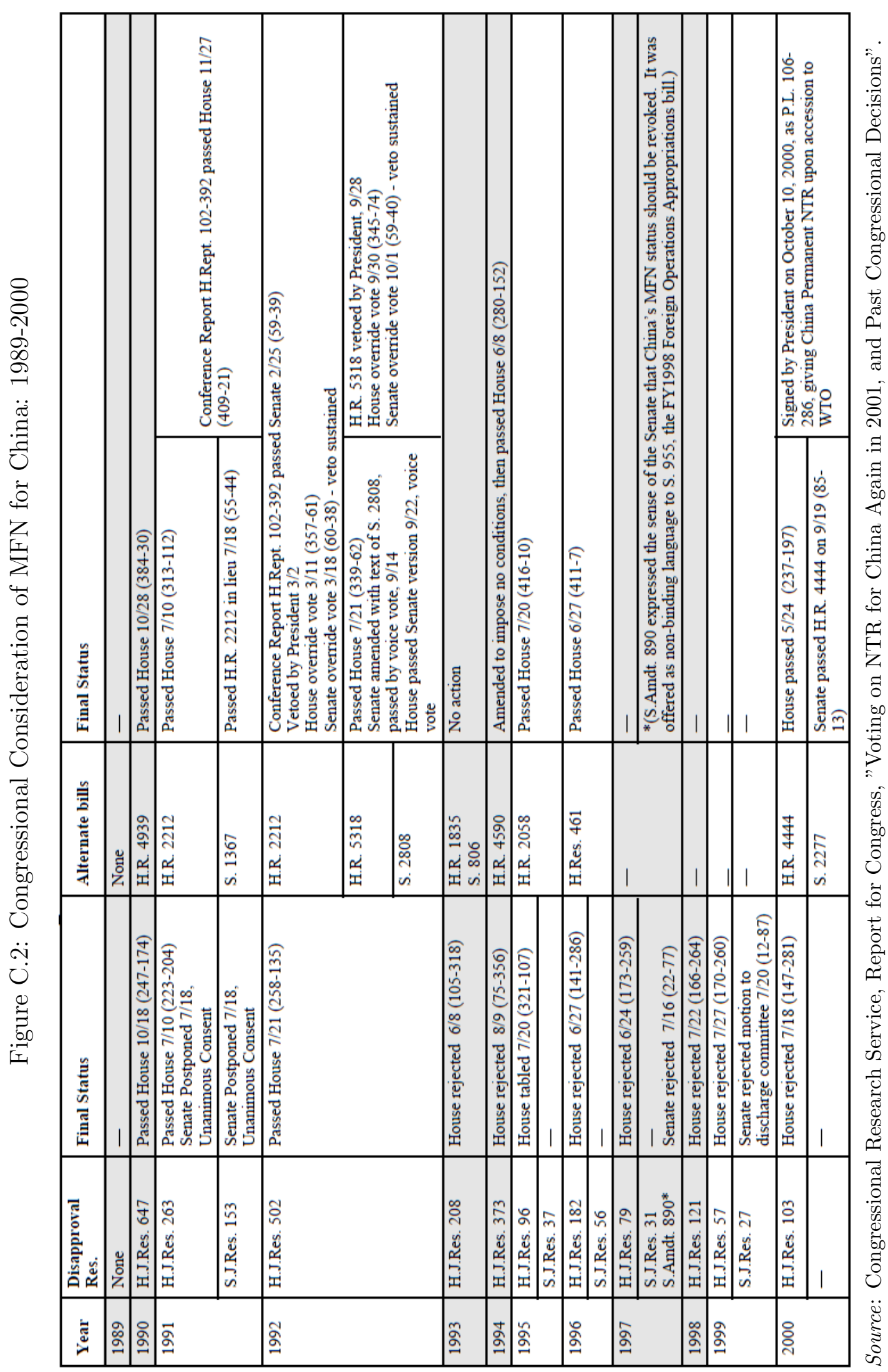


Figure C.3: Estimated Annual Probabilities of Revoked Access to MFN Rates

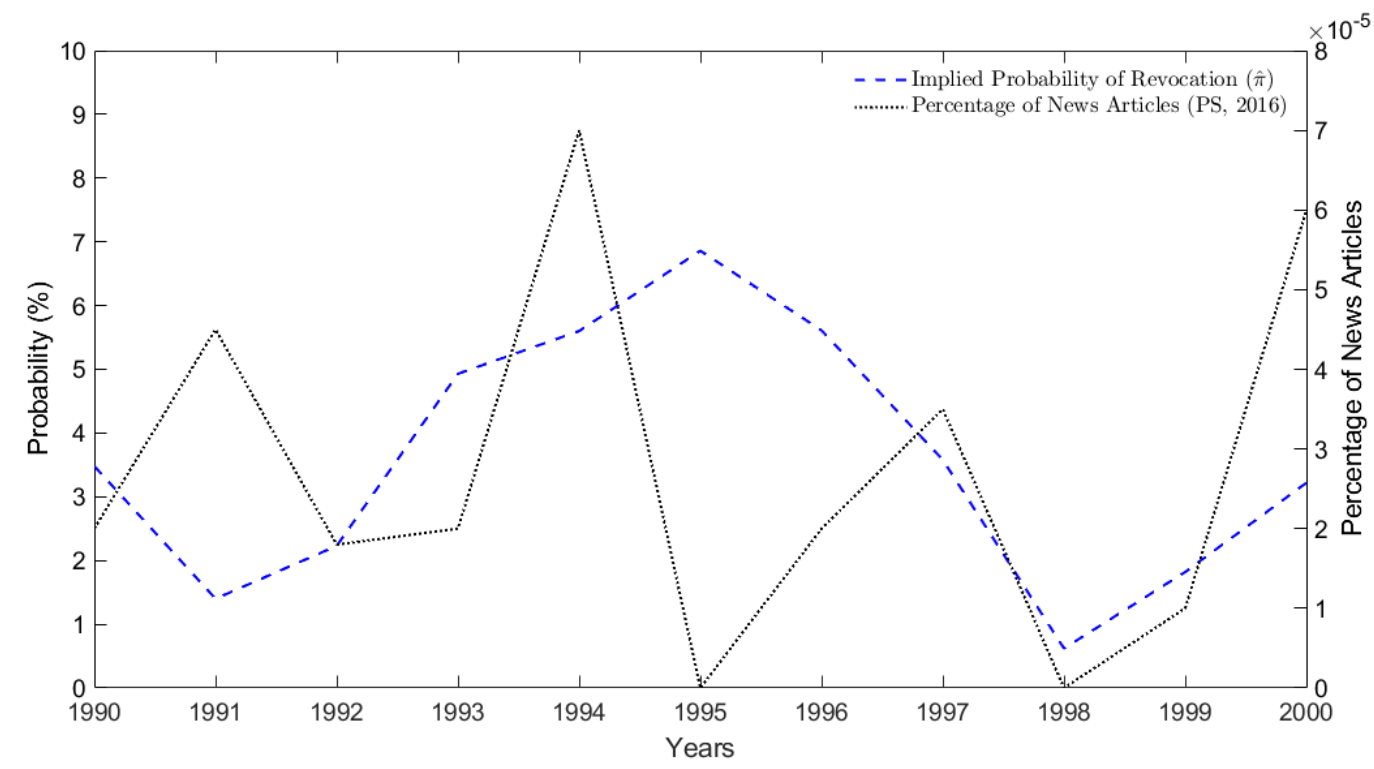

Note: On the left y-axis are the model implied annual probabilities reported in column 4 of Table 8 . On the right y-axis is the TPU measure used in Pierce and Schott (2016) calculated as the percent of news articles of the New York Times, Wall Street Journal, and the Washington Post containing references to the uncertainty of China's MFN status.

Figure C.4: Updated Signal on the Likelihood of Tariff Hike

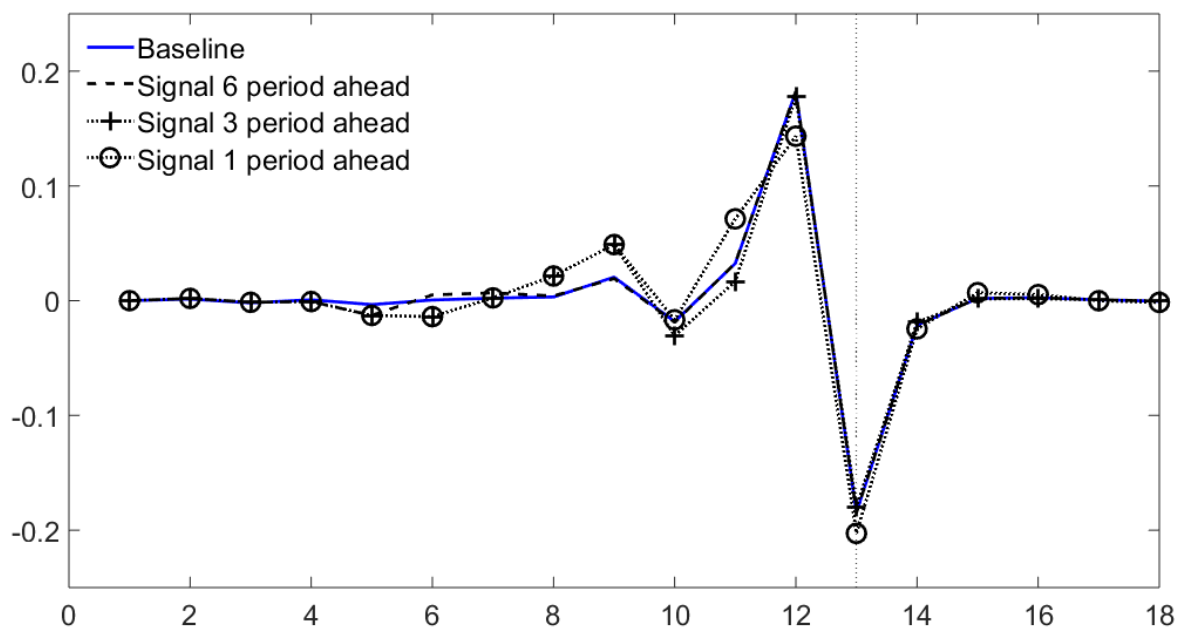

Note: The x-axis are log deviation from the steady state level of imports. The size of the tariff hike is the same for all three cases and the resolution of the uncertainty is set to occur in period 13. 


\section{Figure C.5: Early Resolution of Uncertainty}

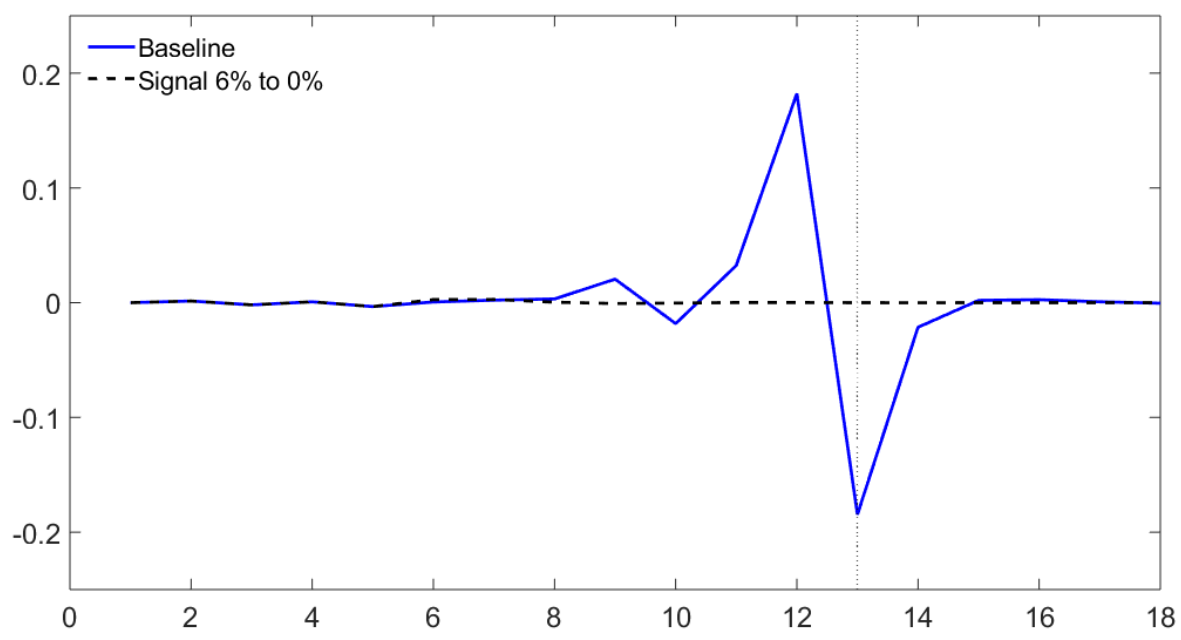

Note: The x-axis are log deviation from the steady state level of imports. The size of the tariff hike is the same for all three cases. While in the baseline case the uncertainty resolves after period 13 , in the other two cases it resolves after the 7 th period. 